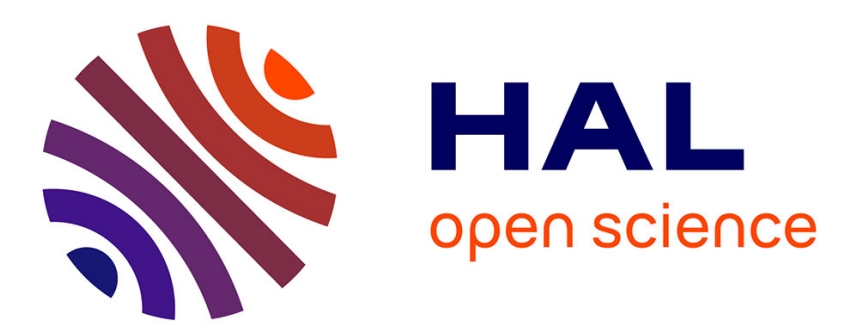

\title{
TiO2 nanoparticles coated with bio-inspired ligands for the safer-by-design development of photocatalytic paints
}

Jérôme Laisney, Aurélie Rosset, Vincent Bartolomei, Daniela Predoi, Delphine Truffier-Boutry, Sébastien Artous, Virginie Berger, Grégory Brochard, Isabelle Michaud-Soret

\section{To cite this version:}

Jérôme Laisney, Aurélie Rosset, Vincent Bartolomei, Daniela Predoi, Delphine Truffier-Boutry, et al.. $\mathrm{TiO} 2$ nanoparticles coated with bio-inspired ligands for the safer-by-design development of photocatalytic paints. Environmental science.Nano, 2021, 8 (1), pp.297-310. 10.1039/d0en00947d . hal03248730

\section{HAL Id: hal-03248730 \\ https://hal.science/hal-03248730}

Submitted on 2 Nov 2021

HAL is a multi-disciplinary open access archive for the deposit and dissemination of scientific research documents, whether they are published or not. The documents may come from teaching and research institutions in France or abroad, or from public or private research centers.
L'archive ouverte pluridisciplinaire HAL, est destinée au dépôt et à la diffusion de documents scientifiques de niveau recherche, publiés ou non, émanant des établissements d'enseignement et de recherche français ou étrangers, des laboratoires publics ou privés. 


\section{$\mathrm{TiO}_{2}$ nanoparticles coated with bio-inspired ligands for the Safer- by-Design development of photocatalytic paints}

Received 00th January 20xx, Accepted 00th January 20xx

DOI: $10.1039 / x 0 x \times 00000 x$

\author{
Jérôme Laisney, ${ }^{a,+*}$ Aurélie Rosset, ${ }^{a, b}$ Vincent Bartolomei, ${ }^{b}$ Daniela Predoi, ${ }^{c}$ \\ Delphine Truffier-Boutry, ${ }^{b}$ Sébastien Artous, ${ }^{b}$ Virginie Bergé, ${ }^{d}$ Gregory Brochard, ${ }^{d}$ \\ and Isabelle Michaud-Soret ${ }^{\text {a* }}$
}

\begin{abstract}
Addition of titanium dioxide nanoparticles $\left(\mathrm{TiO}_{2} \mathrm{NPs}\right)$ in photocatalytic paints represents a promising alternative aiming to mineralize gaseous pollutants, such as volatile organic compounds (VOCs). However, the risks of release of nanoparticles for human health and environmental impact have to be taken carefully into account for their development. To take in account these risks, we develop new way of $\mathrm{TiO}_{2}$ NPs synthesis. Here, we report the electrostatic stabilization in aqueous media with pyrophosphate buffers of different $\mathrm{pH}$ range followed by the coating with bio-inspired molecules (lysine, deferoxamine, dopamine) and polymers (poly-acrylic acid, polyethylene glycol, poly-dopamine) of 4-5 nm spherical photocatalytic TiO ${ }_{2} \mathrm{NPs}$ for the development of safer-by-design photocatalytic paint. Characterization of the so-formed $\mathrm{TiO}_{2}$ nanocomposites by dynamic light scattering (DLS), Fourrier-transformed infrared spectroscopy (FTIR), thermogravimetric analysis (TGA), scanning electron micrography (SEM), energy-dispersive X-ray spectroscopy (EDX) and X-ray photoelectron spectroscopy (XPS) showed the good grafting of the ligands on the $\mathrm{TiO}_{2}$ surface and an enhanced stability in water compared to the pristine $\mathrm{TiO}_{2}$ NPs. Photocatalytic activity of the $\mathrm{TiO}_{2}$ nanocomposites was investigated by following the degradation of methylene blue (MB) under irradiation. Results showed a modulation of the photocatalytic activity (decrease or increase of the MB degradation rate) as function of the nature/binding strength of the bio-inspired coating on the oxide surface. Finally, the most promising nanocomposites were incorporated in paints on which preliminary chalking assays were performed after storage for one year in the dark or in interior daylight.
\end{abstract}

\section{Introduction}

Engineered nanomaterials (ENMs) and their outstanding surface properties, e.g. high surface/volume ratio, exalted surface reactivity, possibility of multi-functionality, have carried out great promises for a variety of industrial and consumers applications, making materials lighter, more robust and more efficient compared to their bulk analogues. ${ }^{1}$ Since their emergence in the 1990's, nanotechnologies have already showed promises in revolutionizing the agriculture, ${ }^{2}$ food, ${ }^{3}$ textiles, ${ }^{4}$ aerospace, ${ }^{5}$ medicine, ${ }^{6}$ or else energy ${ }^{7}$ industries. Nowadays, more than 4330 nano-products are currently on the European market according to the nanodatabase, ${ }^{8}$ with silver and $\mathrm{TiO}_{2}$ among the most used ENMs. ${ }^{9}$ As an example, the paint and coating industry is considering to introduce ENMs in their paint formulation to provide water repellence, scratch resistance, durability and antimicrobial properties to the paints. ${ }^{10}$ In particular, rutile $\mathrm{TiO}_{2}$ microparticles enters frequently in the paint formulation as pigment (whitener). The photocatalytic form (generally of anatase type) can adsorb UV-light and produce hydroxyl radicals in the presence of waters ${ }^{11}$ leading to the degradation of organic

.CEA - Grenoble, LCBM, Bioscience and Biotechnology Institute of Grenoble (BIG), UMR 5249 CEA/CNRS/UGA, 17, rue des Martyrs, 38000 Grenoble, France

b. Univ Grenoble Alpes, CEA, LITEN, DTNM, LMSE, F-38000 Grenoble, France.

National Institute of Materials Physics, Atomistilor 105 bis, Magurele 077125 Romania

d. ALUOS, Les Docks II, 185 Chemin de Saint-Lambert, F-13821 La Penne-surHuveaune, France.

Present address: Department of Plant and Soil Sciences, University of Kentucky, Lexington, KY 40546, USA.

*To whom correspondence should be addressed: jerome.laisney@gmail.com and isabelle.michaud-soret@cea.fr molecules. The use of photocatalytically active $\mathrm{TiO}_{2}$ under nanoparticulate size $\left(\mathrm{TiO}_{2} \mathrm{NPs}\right)^{12}$ in paints was shown to degrade air contaminants such as NOx and VOCs in the presence of indoor light. ${ }^{13}$ However, our recent study on such formulated paints ${ }^{14,} 15$ have reported a degradation of the paint matrix (composed of binders, fillers, pigments and different additives like dispersing, thickeners and antifoam agents dispersed in water). This is due to the very strong photocatalytic activity of small $\mathrm{TiO}_{2} \mathrm{NPs}$ (4-5 nm in diameter) leading to the release of aerosolized particles as well as unwanted organic compounds from oxidized or partially oxidized VOCs (formaldehyde, methanol, acetaldehyde and formic acid) in the air during the use phase or mechanical solicitation. Consequently, there is a possible risk for workers and consumers to be exposed to NPs. This must be taken seriously into account in order to avoid serious health issues ${ }^{16}$ such as encountered for asbestos. Thus, a safer-bydesign approach ${ }^{17}$ must be applied throughout the whole life cycle of self-cleaning paints (i.e. manufacture, use and end of life) ${ }^{18}$ to minimize their environmental and toxicological impact. Furthermore, we showed previously that the particles release is sensitive to the paint formulation. ${ }^{14}$

In this context, we aim to apply a safer-by-design strategy relying on the chemical modification of the $\mathrm{TiO}_{2} \mathrm{NPs}$ used in the formulated self-cleaning paints of our previous study ${ }^{15}\left(\mathrm{TiO}_{2} \mathrm{NPs}\right.$ referenced as P2) in order to: (i) modulate their photo-catalytic properties; (ii) improve their adhesion to the paint matrix and prevent their release, and (iii) reduce their toxicity. Many strategies such as defects introduction, chemical doping, noble metal deposition, dye sensitization or surface modification with ligands of different nature (organic/inorganic species, polymers) were developed in order to tune the photocatalytic properties. ${ }^{19}$ This work only focuses on the coating of the $\mathrm{TiO}_{2} \mathrm{NPs}$ with a selection of bio-inspired ligands. A twostep protocol for embedding the $\mathrm{TiO}_{2} \mathrm{NPs}$ with the different coating 
was developed consisting in the electrostatic stabilization of the $\mathrm{TiO}_{2}$ nanopowder in water by sonication in presence of an electrolyte that increase the electrostatic repulsive force. Then in a second step the addition of the ligand for coating the particles and provide a supplementary steric stabilization. The physico-chemical properties of the so-formed nanocomposites were investigated using various techniques (DLS, FTIR, TGA, XPS) as well as their photo-catalytic activity by following the degradation of methylene blue (MB) under light irradiation. The best nanocomposites will be selected according to specific criteria (photocatalytic performance, stability, affordability), then dispersed in paints to undergo chalking assays after storage for one year in the dark or in interior light conditions. The full characterization of the formulated paints is part of a separate publication. ${ }^{20}$

\section{Materials and Methods}

\section{Chemicals}

$\mathrm{TiO}_{2}$ nanoparticles and chemicals.

CrystalActivPC500 anatase $\mathrm{TiO}_{2}$ nanopowder (Tronox, Stamford, CT, USA), disodium pyrophosphate $\left(\mathrm{Na}_{2} \mathrm{H}_{2} \mathrm{P}_{2} \mathrm{O}_{7}\right.$, purity $\geq 99 \%)$, tetrasodium pyrophosphate $\left(\mathrm{Na}_{4} \mathrm{P}_{2} \mathrm{O}_{7}\right.$, purity $\geq$ 95\%), L-lysine (purity 98\%), deferoxamine mesylate (purity > 92.5\%), 3,4-dihydroxy-L-phenylalanine (purity > 98\%), poly(acrylic acid) $3.5 \mathrm{kDa}$ (PAA), polyethylene glycol of different molecular weight (10 kDa, $3350 \mathrm{Da}, 200 \mathrm{Da}$ referenced in the text as PEG10000, PEG3350 and PEG200), sodium nitrate $\left(\mathrm{NaNO}_{3}\right)$ and nitric acid were all purchased from Sigma Aldrich, USA. CellTak ${ }^{\circledR}$ was purchased from Corning (Corning, NY, USA).

\section{$\mathrm{TiO}_{2}$ nanoparticles coating}

Electrostatic stabilization of $\mathrm{TiO}_{2}$ NPs in aqueous media. (Step 1) Optimal dispersion conditions were obtained for 2-10 mL aqueous suspension of $\mathrm{TiO}_{2} \mathrm{NPs}\left(10 \mathrm{mg} \cdot \mathrm{L}^{-1}\right)$. These suspensions were sonicated for $1 \mathrm{~h}$ (pulse 1s on/off, 80\% amplitude) in a cuphorn system (Vibracell 75041 ultrasonifier, Bioblock Scientific with a Sonics \& Materials high intensity cup-horn), in presence of $5 \mathrm{mM}$ of acidic $\left(\mathrm{Na}_{2} \mathrm{H}_{2} \mathrm{P}_{2} \mathrm{O}_{7}\right.$, referenced in the text as $\mathrm{H}_{2}$ Pyro $)$ neutral $\left(\mathrm{Na}_{2} \mathrm{H}_{2} \mathrm{P}_{2} \mathrm{O}_{7} / \mathrm{Na}_{4} \mathrm{P}_{2} \mathrm{O}_{7}\right.$ mix in a 1:1 v:v ratio) or alkaline $\left(\mathrm{Na}_{4} \mathrm{P}_{2} \mathrm{O}_{7}\right.$, referenced in the text as NaPyro) pyrophosphate buffer.

Embedding and steric stabilization of $\mathrm{TiO}_{2} \mathrm{NPs}$ with the bioinspired coatings. (Step 2)

Ligand solutions were introduced dropwise into the $\mathrm{TiO}_{2} \mathrm{NPs}$ suspension previously stabilized. The solutions were prepared with optimal conditions of concentration and $\mathrm{pH}$, concentration of ligand $\left(C_{\mathrm{L}}\right)$ and volume added $\left(\mathrm{Ti}_{\text {surf }} /\right.$ ligand stoichiometric ratio of $1 / 1$ ) to trigger an exchange ligand reaction between the hydroxylated surface and the ligands (Table S1). The concentration of titanium on surface sites $\left(\mathrm{Ti}_{\text {surf }}\right)$ was determined according to the Equation 1. ${ }^{21}$

$[\mathrm{Ti}]_{\text {surf }}=\left[\mathrm{TiO}_{2}\right] \cdot 12.5 / \mathrm{D}$

Where $\left[\mathrm{TiO}_{2}\right]$ represents the molar concentration $\left(\mathrm{mol}^{\left.-\mathrm{L}^{-1}\right)}\right.$ of $\mathrm{TiO}_{2}$, and $\mathrm{D}$, the particle diameter in Ångstrom. We estimated a concentration of $\mathrm{Ti}_{\text {surf }}$ of $39 \mathrm{mM}$ taking into consideration a primary particle size of $4 \mathrm{~nm}$ and a concentration of $10 \mathrm{mg} \cdot \mathrm{mL}$ 1. The $\mathrm{pH}$ was also adjusted in order to fully protonate (PAA) or deprotonate (lysine, deferoxamine, Dopa, PEGs) the ligand for an optimal reactivity with the negatively or positively charged $\mathrm{TiO}_{2}$ surface. The mixture was then stirred at $60^{\circ} \mathrm{C}$ for $1 \mathrm{~h}$ in an Omni station OS1025 reactor (Electrothermal, Fisher Scientific, Waltam, MA, USA) allowing homogeneous heating of the solution. The particles were collected by centrifugation at maximum speed for $10 \mathrm{~min}$, washed three times with water to remove unreacted ligand and dried overnight at $50{ }^{\circ} \mathrm{C}$ in an oven. The particles were then stored in the dark at $4{ }^{\circ} \mathrm{C}$.

\section{Characterization}

Scanning electron microscopy (SEM).

The size and morphology of $\mathrm{TiO}_{2} \mathrm{NPs}$ were investigated by ultraHigh Resolution Scanning Electron Microscopy (HR-SEM, LEO 1530 , Germany). Images were acquired with a working distance of $3.6 \mathrm{~mm}$, an accelerating voltage of $5 \mathrm{kV}$, a magnification of $x$ $100 \mathrm{~K}$ and a diagram aperture of $30 \mu \mathrm{m}$. The elementary chemical composition of $\mathrm{TiO}_{2}$ NPs was analyzed by Energy Dispersive X-ray spectrum (EDX, QUANTAS EDS, Bruker Nano assisted software ESPRIT, USA) in the SEM. The working distance and accelerating voltage were respectively raised to 8 $\mathrm{mm}$ and $15 \mathrm{kV}$.

\section{Dynamic light scattering (DLS).}

The hydrodynamic radius of the nanoparticles (averaged in \% intensity or \% mass) and polydispersity were measured by DLS using a DynaPro NanoStar from Wyatt Technology (Santa Barbara, CA, USA). The suspensions of NPs were diluted in ultrapure water at a concentration of $100 \mu \mathrm{g} \cdot \mathrm{mL}^{-1}$ and filtered on a $0.45 \mu \mathrm{m}$ membrane prior to measurement to get rid of non-dispersible aggregates.

\section{Zeta potential.}

Surface charge was evaluated by electrophoretic mobility using a Zetasizer Nano ZSP (Malvern Instruments, Worcestershire, UK). $50 \mu \mathrm{g} \cdot \mathrm{mL}^{-1}$ of $\mathrm{TiO}_{2}$ NPs were sonicated for $5 \mathrm{~min}$ in $13 \mathrm{~mL}$ of deionized water and $10 \mathrm{mM}$ of sodium nitrate $\left(\mathrm{NaNO}_{3}\right)$. Electrophoretic mobility was measured from low $\mathrm{pH}$ by adding small amount of nitric acid $\mathrm{HNO}_{3}$ to adjust the $\mathrm{pH}$.

\section{Fourrier-transformed infrared (FTIR) spectroscopy.}

The presence of the coating on the $\mathrm{TiO}_{2}$ surface was verified by FTIR. FTIR spectra were recorded at RT on transmission mode (scan resolution: $4 \mathrm{~cm}^{-1}$ ) with $1 \mathrm{mg}$ of dried powders pelleted with $99 \mathrm{mg}$ of $\mathrm{KBr}$ and using a Spectrum 100 PerkinElmer spectrometer (PerkinElmer, Waltham, MA. USA)

\section{Thermogravimetric analysis (TGA).}

Quantification of the coating surrounding the $\mathrm{TiO}_{2} \mathrm{NPs}$ was measured by TGA using a SDT Q600 from TA instruments (Water Corporation, Milford, MA, USA). The samples followed up a heat cycle between 20 and $800{ }^{\circ} \mathrm{C}$ at a heating rate of $10^{\circ} \mathrm{C} / \mathrm{min}$. The weight derivative as a function of the temperature (dashed curves) was represented along with the weight variation for a 
finer analysis of the weight fluctuation over the temperature range.

$X$-ray photoelectron spectroscopy (XPS) analysis.

The grafting mode was determined by XPS using a $1486.61 \mathrm{eV}$ Al Ka monochromatic X-ray source (SPECS $\mathrm{GmbH}$, Berlin, Germany). Survey $\left(0-1400 \mathrm{~cm}^{-1}\right)$ and high-resolution (C1s, Ti2p and $\mathrm{O} 1 \mathrm{~s}$ ) spectra were recorded. The atomic percentage of each element was determined from the high-resolution spectra using Spectral Data Processor software. The binding energy of spectra was calibrated from carbon C1s peak at $285 \mathrm{eV}$ corresponding to the hydrocarbon ( $\mathrm{C}-\mathrm{C} / \mathrm{C}-\mathrm{H})$.

\section{Photocatalytic activity.}

The photo-catalytic activities of the nanocomposites were measured with $\mathrm{MB}$ as a target molecule under UV-Vis irradiation. The degradation of $\mathrm{MB}$ in presence of $\mathrm{TiO}_{2} \mathrm{NPs}$ was followed according to the evolution of the absorbance at 655 $\mathrm{nm}$ measured by UV-visible spectroscopy (Cary 100, Agilent technologies, Santa Clara, CA, USA). The experimental setup consists of a Xe source $(\mathrm{P}=300 \mathrm{~W}, \lambda>300 \mathrm{~nm}$ ) (Newport, MKS Instruments Inc., Andover, MA, USA) equipped with a liquid filter filtering wavelengths greater than $800 \mathrm{~nm}$ to prevent heating and evaporation of the solution. $10 \mathrm{mg} \cdot \mathrm{mL}^{-1}$ of $\mathrm{TiO}_{2} \mathrm{NPs}$ suspensions in water or in $5 \mathrm{mM}$ NaPyro were prepared by weighing a mass of $\mathrm{TiO}_{2}$ accordingly to the TGA results for $\mathrm{TiO}_{2}$ concentration in each sample then sonicated for $1 \mathrm{~h}$ (pulse $1 \mathrm{~s}$ on/off, $80 \%$ amplitude) in a cup-horn system. The $\mathrm{TiO}_{2}$ suspension was then diluted in $2 \mathrm{~mL}$ of a $12.5 \mu \mathrm{g} \cdot \mathrm{mL}^{-1}$ aqueous solution of $\mathrm{MB}$ to reach $\mathrm{TiO}_{2} \mathrm{NPs}$ concentrations ranging between $0-100 \mu \mathrm{g} \cdot \mathrm{mL}^{-1}$. The solution was then placed in a quartz cuvette and irradiated under stirring at a power between 2.1 and 2.2 suns ( 210 and $220 \mathrm{~mW} \cdot \mathrm{cm}^{-2}$ ). UV-vis spectrum in the 200-800 $\mathrm{nm}$ range was recorded at different time points over a period of $2 \mathrm{~h}$.

\section{Paint formulation and chalking assay.}

Photocatalytic paints were formulated with $\mathrm{TiO}_{2} \mathrm{NPs}$ and $\mathrm{TiO}_{2}$ NPs coated with Dopa, PEG3350 and PAA. Slurries of $\mathrm{TiO}_{2}$ nanopowders with a $\mathrm{TiO}_{2}$ concentration of 35 wt\% were prepared in $5 \mathrm{mM}$ neutral pyrophosphate buffer to ensure optimal dispersion conditions. The particles were then incorporated in the paint as described in ref ${ }^{20}$ with a final $\mathrm{TiO}_{2}$ NP content of $3.5 \mathrm{wt} \%$. The formulated paints were then applied on a Leneta substrate using a manual film applicator with a wet thickness of $150 \mu \mathrm{m}$. The paints were then stored at room temperature for one year in the dark or under interior day light before undergoing a chalking assay according to the NF EN ISO norm 4628-3. Experimentally, the chalking resulting from ageing was removed with a tape then examined on a contrasting background. The degree of chalking was evaluated using a reference scale quotation. (a)

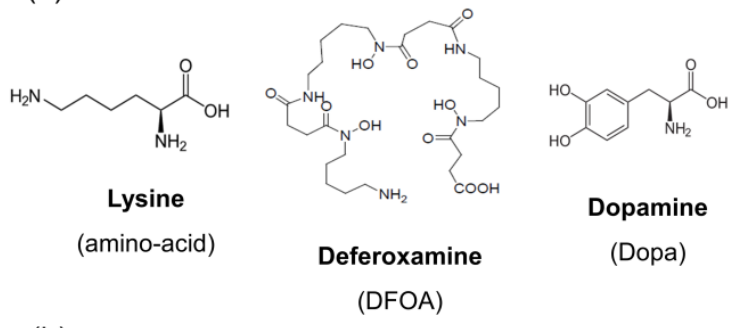

(b)

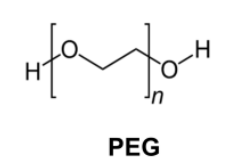

$200,3350,10000$ g.mol $\mathbf{m}^{-1}$

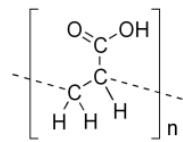

PAA $1800 \mathrm{~g} \cdot \mathrm{mol}^{-1}$

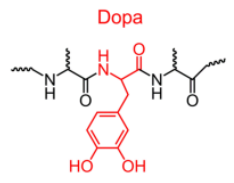

CellTak ${ }^{\circledR}$ (Poly-dopamine)

\section{Expected Binding Affinity with $\mathrm{TiO}_{2}$}

Fig. 1: Selected bio-inspired molecules (a) and polymers (b) and their expected binding affinity with the $\mathrm{TiO}_{2}$ NPs surface.

\section{Results and discussion}

\section{Electro-steric stabilization of photocatalytic $\mathrm{TiO}_{2} \mathrm{NPs}$ with} bio-inspired ligands

\section{Selection of bio-inspired ligands.}

The selected bio-inspired coatings are presented in Fig. 1. They were chosen according to specific criteria such as biocompatibility, adhesion properties and hydrophilicity to reduce the toxicity of the particles, adhere to the paint matrix via supplementary bonds and work under mild conditions such as in aqueous medium. They also possess different binding mechanism (covalent versus non-covalent) and functional groups to vary the binding strength on the $\mathrm{TiO}_{2}$ surface. These coatings can be divided into two categories: (a) low molecular weight natural ligands and (b) bio-compatible polymers. Among the molecular coatings (Fig. 1a) were selected the lysine aminoacid, the deferoxamine siderophore (DFOA) and the dopamine (Dopa) molecule, well known for its ability to bind iron and $\mathrm{TiO}_{2}$ films via the catechol functional group. ${ }^{22}$ Since these coatings possess an affinity with $\mathrm{Fe}(\mathrm{III})$, we expect these molecules to bind covalently via a coordination bond to the Ti(IV) sites on the surface of the particles. For the bio-polymers category (Fig. 1b), polyethylene glycol (PEG) and polyacrylic acid (PAA) were chosen due to their regular use in the synthesis of nanoparticles conferring them stabilization, biocompatibility and bioadhesion properties. ${ }^{23-29}$ In contrast to the previous class of coatings, these polymers bind to the surface via a multiplicity of weaker interactions such as hydrogen bonds or van der Waals contacts. Different molecular weights of PEG were selected $\left(\mathrm{M}_{\mathrm{W}}\right.$ $=200,3350,10000 \mathrm{~g} \cdot \mathrm{mol}^{-1}$ ) to vary the thickness of the coating layer around the $\mathrm{TiO}_{2}$ surface. Finally, we chose a derivative of Mfp (Mussel Foot Protein) type proteins that possess considerable adhesion properties on any kinds of surfaces (dry 
or wet) related to the presence of Dopa and Iysine within the protein chain. ${ }^{30-32}$ In particular, CellTak ${ }^{\circledR}$ is a commercial polydopamine Mfp protein used for cells adhesion on substrates and containing 5\% Dopa formed by the repetition of the decapeptide (Ala-Lys-Pro-Ser-Tyr-Hyp-Hyp-Thr-Dopa-Lys) ${ }_{x}(x=$ 80 - 100). ${ }^{33}$

\section{Electrostatic stabilization of the $\mathrm{TiO}_{2}$ NPs with an electrolyte.}

SEM image and EDX spectrum of the $\mathrm{TiO}_{2} \mathrm{NPs}$, presented in Fig. S1, showed the presence of large clusters of a few microns composed of spherical NPs with a diameter of approximately 4$5 \mathrm{~nm}$, as already reported in our previous study. ${ }^{15}$ For a uniform and efficient coating around the NPs, an effective method is needed first to break the clustering of particles ${ }^{34}$ then to stabilize the suspension in aqueous medium for allowing the ligand to interact with the oxide surface. Pyrophosphates have proven to be an effective electrolyte for the dispersion of $\mathrm{TiO}_{2}$ nanopowder. ${ }^{33}$ The acidic $\left(\mathrm{Na}_{2} \mathrm{H}_{2} \mathrm{P}_{2} \mathrm{O}_{7}, \mathrm{pH} 4.5\right)$ and alkaline forms $\left(\mathrm{Na}_{4} \mathrm{P}_{2} \mathrm{O}_{7}, \mathrm{pH}\right.$ 8.5) of pyrophosphate, designed respectively as $\mathrm{H}_{2}$ Pyro and NaPyro, open the possibility for two synthetic routes according to the physico-chemical properties of the bio-inspired ligands (e.g. acceptor or electron donor, $\mathrm{pH}$ of the ligand in aqueous solution). The zeta potential of the particles measured as a function of the $\mathrm{pH}$ (Fig. S2) gives an estimation of the point of zero charge of the $\mathrm{TiO}_{2} \mathrm{NPs}$ in water located around $\mathrm{pH}$ 5.0. Based on this result, dispersion in $\mathrm{H}_{2}$ Pyro will protonate the water layer on the particle surfaces and lead to a positively charged $\mathrm{TiO}_{2}$ surface $(\xi=+5-10 \mathrm{mV})$ while the basic pyrophosphate form will lead to the reduction of the surface water layer with the presence of hydroxyl ions and negative charges $(\xi=-35 \mathrm{mV})$. Contrary to pure dispersions in water leading to a rapid sedimentation of the powder, the suspensions in presence of pyrophosphate remains stable. DLS measurements performed on the suspensions (Fig. 2) shows the different particle sizes population in mass-weighted average. After sonication, two populations were observed for both conditions. A population predominant in mass (main peak) of small particles with a hydrodynamic radius measured in the 3-5 $\mathrm{nm}$ range, i.e. compatible with the size of the primary particles (2-2.5 $\mathrm{nm}$ radius), and clusters of a hundred of nanometers. In addition to the good dispersion in the particle size (PDI of the main peaks $<0.05)$, the colloidal solutions are stable from several hours to several days with a slightly improved stability when the particles were sonicated in presence of the basic pyrophosphate form. The improved stability of the particles can be easily explained by the value of the zeta potential of the particles with a higher global surface charge at $\mathrm{pH} 8.5$ compared to $\mathrm{pH} 4.5$ providing higher repulsive electrostatic forces. Indeed, according to the Derjaguin-Landau-Vervey-Overbeek (DLVO) theory, ${ }^{35}$ the aggregation or dispersion of particles in solution is governed by the relative intensity of two main forces: (i) attractive force of van der Waals and (ii) repulsive electrostatic force. In an aqueous medium, the low overall charge of the nanoparticles surrounded only by water molecule does not provide enough repulsive force to avoid the rapid aggregation of the particles in solution.

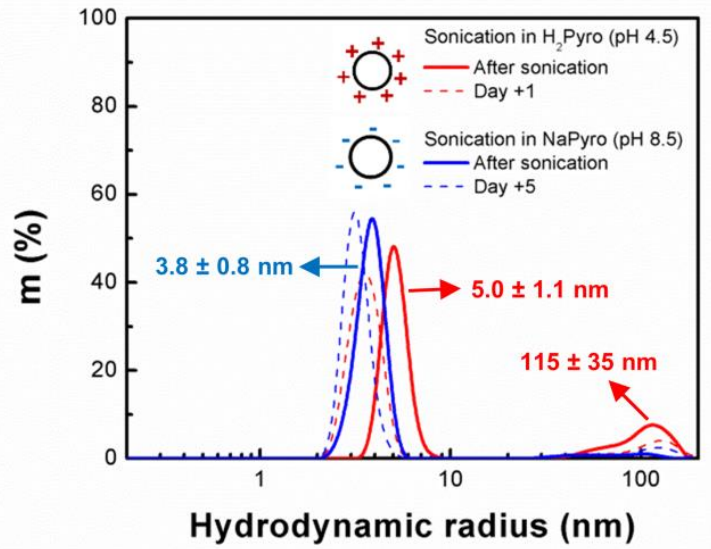

Fig.2: Hydrodynamic radius measured by DLS (mass-weighted average) of an aqueous suspension of $\mathrm{TiO}_{2} \mathrm{NPs}$ sonicated in presence of $5 \mathrm{mM}$ pyrophosphate in acid $\left(\mathrm{H}_{2} \mathrm{Pyro}, \mathrm{pH}=4.5\right.$ ) or basic form (NaPyro, $\mathrm{pH}=8.5$ ). Measurements performed after sonication (-) and before aggregation (- - -).

\section{Coating of $\mathrm{TiO}_{2} \mathrm{NPs}$ with the bio-inspired ligands.}

After dispersion and stabilization in presence of pyrophosphate, a solution of ligand was added dropwise to the $\mathrm{TiO}_{2} \mathrm{NPS}$ suspension with optimized ligand concentration $\mathrm{C}_{\mathrm{L}}$ and $\mathrm{pH}$ (Table S1). As an example, PAA has a pKa of 4.5 meaning that the functional groups of the acrylic acid monomer are undissociated and positively charged below $4.5 .{ }^{36}$ As the $\mathrm{pH}$ of a PAA solution at $C_{L}$ is 2 , the $\mathrm{TiO}_{2}$ NPs were then sonicated in presence of the basic form of pyrophosphate to provide negative charges to the surface and trigger an electrostatic reaction between the $\mathrm{TiO}_{2} \mathrm{NPs}$ and the polymer. Concerning the reaction of Dopa on the $\mathrm{TiO}_{2}$ surface, it is reported in the literature ${ }^{37}$ that Dopa binds the Ti(IV) sites according to two coordination modes depending of the $\mathrm{pH}$. The first one so-called salicylate mode at acidic $\mathrm{pH}$ in which the protonated or partially protonated Dopa binds the Ti(IV) via hydrogen bonds. The second one, a catecholate mode $(\mathrm{pH}>7)$ in which the binding involved two coordination bonds from the two deprotonated oxygens. The catecholate binding mode on the photocatalytic properties was only investigated by preparing the Dopa in basic medium (deprotonated form). In the particular case of the CellTak $^{\circledR}$ coating, the attachment on the surface is achieved after the sudden raise of the $\mathrm{pH}$ from neutral to basic.

After reaction, the nanocomposites powders involving the covalent grafting (biomolecules and CellTak ${ }^{\circledR}$ coatings) exhibits different color from pale yellow to dark brown compared to the original bright white $\mathrm{TiO}_{2} \mathrm{NPs}$ powder and the non-covalent grafting composites (PEG and PAA). These different optical properties can be an indicator of the good grafting of the molecules on the surface as covalent grafting involves coordination bonds creating charge transfer bands (Ligand-toMetal type) in the visible domain or the polarization of the dipole moment. ${ }^{38}$ The evolution of the NPs size after addition of the bio-inspired ligands was followed by DLS (Fig. S3). After addition of the bio-inspired ligands and ageing in the dark, the population of the particles progressively evolved over time toward clusters of a hundred of nanometers before their aggregation. From this dataset, we estimated the stability of the 
different suspensions after their electro-steric stabilization (Table 1). It is worth noticing that the stability of the NPs was improved when coated with the different bio-inspired ligands compared to $\mathrm{TiO}_{2} \mathrm{NPs}$ suspended in water and pyrophosphate. The particles coated with Dopa, PEG3350 and PAA present the best stability with a lifetime in the dark superior to 6 months.
However, the particles coated with Lysine, PEG200, and PEG10000 aggregates after only one month. In the case of particles coated with CellTak ${ }^{\circledR}$, the addition of ligand causes the formation of large size assemblies that rapidly settles down. After reaction, the nanocomposites were collected by centrifugation for further characterization.

Table 1: Stability and photo-catalytic properties of the $\mathrm{TiO}_{2}$ nanocomposites as a function of the dispersing medium and the bio-inspired coatings

\begin{tabular}{|c|c|c|c|c|}
\hline Coating & Electrolyte & Stability ${ }^{\phi}$ & $\begin{array}{c}\mathrm{t}_{1 / 2}(\min ) \\
\left(50 \mu \mathrm{g} \cdot \mathrm{mL}^{-1}\right)^{\psi}\end{array}$ & $\begin{array}{c}\text { Photo-catalytic activity } \\
\text { (\%) }\end{array}$ \\
\hline- & - & A few minutes & 27.3 & - \\
\hline- & $\mathrm{H}_{2}$ Pyro & A few hours & - & - \\
\hline- & NaPyro & A few days & - & - \\
\hline Lysine & $\mathrm{H}_{2}$ Pyro & 2 weeks & 34.2 & -25 \\
\hline DFOA & $\mathrm{H}_{2}$ Pyro & 1 month & 45.8 & -68 \\
\hline Dopa & NaPyro & $>6$ months & 85.6 & -214 \\
\hline PEG200 & $\mathrm{H}_{2}$ Pyro & 1 month & 33.1 & -21 \\
\hline PEG3350 & $\mathrm{H}_{2}$ Pyro & $>6$ months & 48.8 & -78 \\
\hline PEG10000 & $\mathrm{H}_{2}$ Pyro & 1 month & 36.4 & -33 \\
\hline PAA & NaPyro & $>6$ months & 22.2 & +18 \\
\hline CellTak $^{\circledR}$ & Pyro neutral buffer & Aggregation & 67.8 & -148 \\
\hline
\end{tabular}

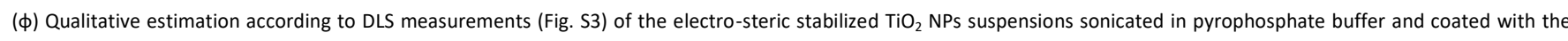

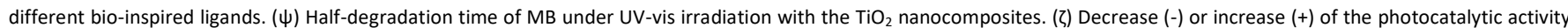
(PA) of the $\mathrm{TiO}_{2}$ nanocomposites was determined from $\mathrm{T}_{1 / 2}(\mathrm{MB})$ of the composites compared to $\mathrm{T}_{1 / 2}(\mathrm{MB})$ of the pristine $\mathrm{TiO}_{2} \mathrm{NPs}$ according to the formula $\mathrm{PA}=\left(\mathrm{T}_{1 / 2}\right.$ composite $-\mathrm{T}_{1 / 2}$ pristine $\mathrm{TiO}_{2} \mathrm{NPs}$ ). $100 / \mathrm{T}_{1 / 2}$ pristine $\mathrm{TiO}_{2} \mathrm{NPs}$.

\section{Characterization of the $\mathrm{TiO}_{2}$ nanocomposites}

Grafting of the ligands by FTIR spectroscopy.

FTIR spectra of the powders were collected to verify the good grafting of the bio-inspired ligands on the surface. Fig. 3 shows the FTIR spectra in the $1850-1000 \mathrm{~cm}^{-1}$ range for the pristine $\mathrm{TiO}_{2} \mathrm{NPs}$ and the so-formed nanocomposites after ligands addition. In this range, characteristics bands attributed to the $\mathrm{TiO}_{2}$ NPs can be found at $1630 \mathrm{~cm}^{-1}$ and $1114 \mathrm{~cm}^{-1}$ corresponding to the $\mathrm{Ti}\left(\mathrm{TiO}_{2}\right)-\mathrm{O}\left(\mathrm{H}_{2} \mathrm{O}\right)$ and $\mathrm{O}\left(\mathrm{TiO}_{2}\right)-\mathrm{O}\left(\mathrm{H}_{2} \mathrm{O}\right)$ vibrations between the titanium or oxygen from the $\mathrm{TiO}_{2}$ surface and the oxygen from the hydroxyl layer. According to the literature, ${ }^{39}$ the characteristics vibration band of $\mathrm{TiO}_{2}$ observed at $1400 \mathrm{~cm}^{-1}$ can be attributed to the vibration of Ti-O bonds inside the $\mathrm{TiO}_{2}$ crystal lattice. Other characteristic vibrations of $\mathrm{TiO}_{2}$ outside this range can be found at $660 \mathrm{~cm}^{-1}$ (vTi-O-Ti) and between 3700 and $2600 \mathrm{~cm}^{-1}$, attributed to the hydrogens vibration from the hydroxyl layer (Fig. $\$ 4$ for the full range FTIR spectra). In addition to the characteristic vibrational bands of $\mathrm{TiO}_{2}$, additional bands are visible in the spectra of the nanocomposites. A clear additional band appears in the $\mathrm{TiO}_{2-}$ PAA nanocomposite spectrum (Fig. 3e) that can be attributed to the $\mathrm{C}=\mathrm{O}$ from the carboxylate functional group of the acrylic acid monomer. Similarly, the $\mathrm{TiO}_{2}-\mathrm{PEG}$ nanocomposite spectrum (Fig. 3d) presents an intense band at $1106 \mathrm{~cm}^{-1}$ that could be due to the $\mathrm{O}-\mathrm{O}$ vibration band between the PEG polymeric chains and the $\mathrm{O}$ from the $\mathrm{TiO}_{2}$ surface or the hydroxyl layer. The $\mathrm{TiO}_{2}$-Dopa (Fig. 3c) and other bio-molecular coatings (Lysine, Fig. 3a; DFOA, Fig. 3b) lets appear additional vibration bands at $1490 \mathrm{~cm}^{-1}$ and $1270 \mathrm{~cm}^{-1}$ that can be attributed to the vibrations of $\mathrm{C}-\mathrm{NH}_{2}$ and $\mathrm{C}-\mathrm{O}$ functional groups present in these ligands. The assignment of the bands for the other coatings can be found in Table S2. As those additional bands are characteristic of functional groups and chemical bonds present in the different ligands, FTIR characterization could indicate their good grafting on the surface.

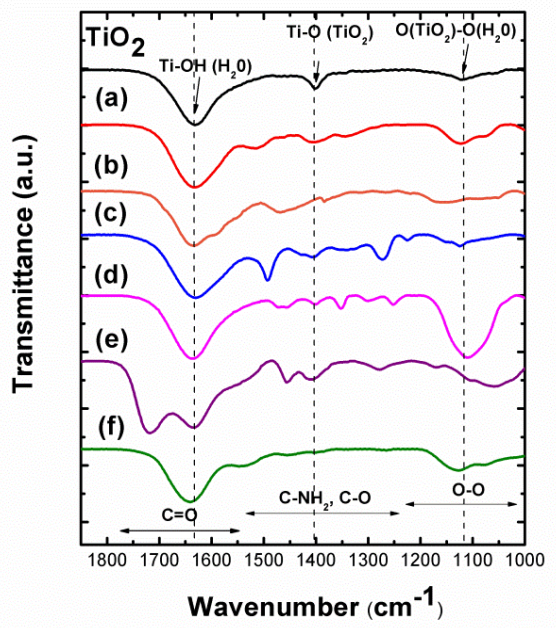

Fig. 3: FTIR spectra ( $\mathrm{KBr}$ pellet) in the $1850-1000 \mathrm{~cm}^{-1}$ of the $\mathrm{TiO}_{2} \mathrm{NPs}$ (in black) and $\mathrm{TiO}_{2}$ NPs coated with (a) Lysine, (b) Deferoxamine (DFOA), (c) Dopa (catecholate), (d) PEG3350, (e) PAA and (f) CellTak ${ }^{\circledR}$. The spectra were normalized according to the peak at $1630 \mathrm{~cm}^{-1}\left(\mathrm{v}_{\mathrm{Ti}-\mathrm{OH}}\right)$. 
Quantification of the coating by thermogravimetric analysis (TGA).

To confirm and quantify the coating around the $\mathrm{TiO}_{2} \mathrm{NPs}$ surface, thermogravimetric analysis (TGA) was performed on the nanocomposites (bio-molecules, Fig. $4 \mathrm{a}$ and bio-polymers, Fig. 4b). In the thermograms were observed several weight losses associated to the departure of chemical species during the thermal cycle. A first weight loss associated to the dehydration of the samples $\left(\mathrm{T}_{\text {water }}<100^{\circ} \mathrm{C}\right.$ ) was observed for all the nanocomposites. After dehydration, a weak weight loss was observed soon after $\left(\mathrm{T}=172.6^{\circ} \mathrm{C}\right)$ for the pristine $\mathrm{TiO}_{2} \mathrm{NPs}$ that could potentially be associated to the impurities surrounding the NPs surface. Additional weight losses were observed in the thermograms of nanocomposites at a temperature relatively close to the temperature observed in the case of the departure of the free bio-inspired ligands (Fig. S5) allowing us to unambiguously confirm the good grafting of the ligands on the surface. At $800{ }^{\circ} \mathrm{C}$, all the different organic coatings were sublimated and the remaining product/weight was associated to $\mathrm{TiO}_{2}$. All the different features that can be extracted from the thermograms are presented in Table 2. The nanopowders contain between 6 and 12 wt\% of water depending on the drying as the departure of water occurs below $50{ }^{\circ} \mathrm{C}$ for most of them. The weight content of $\mathrm{TiO}_{2}$ in the different samples, including the initial nanopowder, is found below $85 \mathrm{wt} \%$. (a)
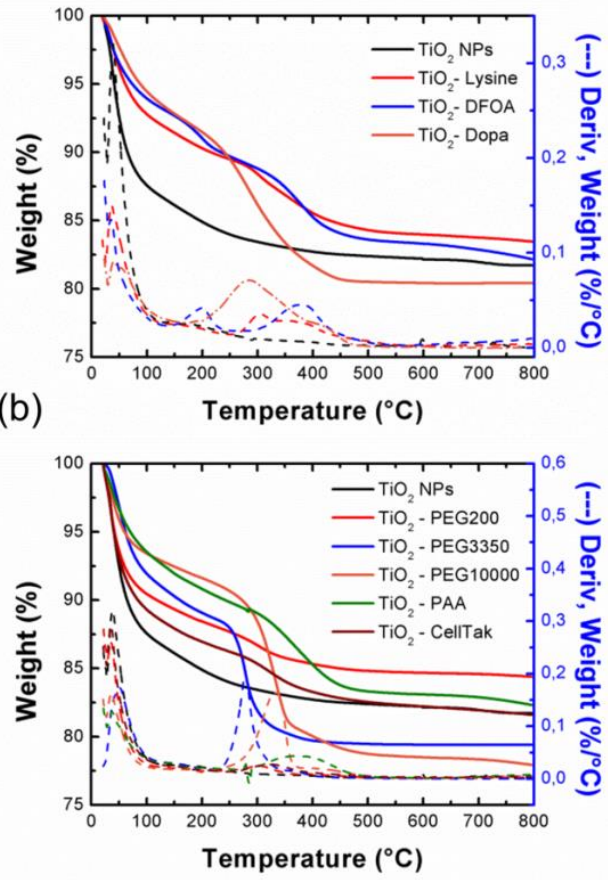

Fig. 4: Thermograms of the $\mathrm{TiO}_{2} \mathrm{NPs}$ (in black) and $\mathrm{TiO}_{2} \mathrm{NPs}$ coated with the different bio-inspired molecules (a) and polymers (b). Dash curve: derivative function of the weight as a function of the temperature.

Table 2: Dehydration temperature ( $\left.T_{\text {water }}\right)$, thermal decomposition of the ligand ( $\left.\mathrm{T}_{\text {Ligand }}\right)$, decomposition temperature of the ligand coated on the $\mathrm{TiO}_{2}$ surface $\left(\mathrm{T}_{\text {coating }}\right)$, and global composition of the $\mathrm{TiO}_{2}$ nanocomposites (water, coating and $\mathrm{TiO}_{2}$ contents) extracted from the thermograms.

\begin{tabular}{|c|c|c|c|c|c|c|}
\hline Sites & $\begin{array}{c}\mathrm{T}_{\text {water }} \\
\left({ }^{\circ} \mathrm{C}\right)\end{array}$ & $\begin{array}{c}T_{\text {Ligand }} \\
\left({ }^{\circ} \mathrm{C}\right)\end{array}$ & $\begin{array}{c}\mathrm{T}_{\text {coating }} \\
\left({ }^{\circ} \mathrm{C}\right)\end{array}$ & $\begin{array}{l}\text { Water content } \\
\text { (wt\%) }\end{array}$ & $\begin{array}{l}\text { Coating content } \\
\text { (wt\%) }\end{array}$ & $\begin{array}{c}\mathrm{TiO}_{2} \text { content } \\
\text { (wt\%) }\end{array}$ \\
\hline $\mathrm{TiO}_{2}$ & 37.9 & N.A. & - & 12 & - & 82 \\
\hline $\mathrm{TiO}_{2}$-Lysine & 35.5 & N.A. & 303.1 & 8 & 5 & 83.5 \\
\hline $\mathrm{TiO}_{2}-\mathrm{DFOA}$ & 35.1 & $\begin{array}{l}208.0 \\
387.6\end{array}$ & $\begin{array}{l}200.9 \\
377.3\end{array}$ & 6.5 & $6-7$ & 82 \\
\hline $\mathrm{TiO}_{2}-\mathrm{Dopa}$ & 38.7 & $\begin{array}{l}280.1 \\
501.6\end{array}$ & $\begin{array}{l}280.2 \\
405.6\end{array}$ & 10 & 2.5 & 81.5 \\
\hline $\mathrm{TiO}_{2}-\mathrm{PEG} 200$ & 36.2 & 215.8 & 307.4 & 10 & 2 & 84 \\
\hline $\mathrm{TiO}_{2}-\mathrm{PEG} 3350$ & 80.0 & 256.4 & 277.0 & 6 & 17 & 76 \\
\hline $\mathrm{TiO}_{2}-\mathrm{PEG} 10000$ & 36.6 & 251.3 & 333.9 & 7 & 10 & 78 \\
\hline $\mathrm{TiO}_{2}-\mathrm{PAA}$ & 36.8 & $\begin{array}{l}246.0 \\
315.4 \\
505.6\end{array}$ & 378.1 & 7 & $6-7$ & 82 \\
\hline $\mathrm{TiO}_{2}-$ CellTak & 36.8 & N.A. & 323.6 & 11.5 & 3 & 82 \\
\hline
\end{tabular}


Adsorption mode and thickness of the coating by X-ray photoelectron spectroscopy (XPS).

The $\mathrm{TiO}_{2}$ nanocomposites were analyzed with XPS to determine the grafting mode of the bio-inspired ligands on the $\mathrm{TiO}_{2}$ surface. The high-resolution XPS spectra of C1S, Ti2p and O1s region of the pristine and coated $\mathrm{TiO}_{2} \mathrm{NPs}$ are represented in

Fig. 5. The carbon C1s peak was composed of three peaks at $284.82 \pm 0.04 \mathrm{eV}, 286.1 \pm 0.45 \mathrm{eV}$ and $289.15 \pm 0.45 \mathrm{eV}$ binding energies. The first peak was associated to $\mathrm{C}-\mathrm{C}$ or $\mathrm{C}-\mathrm{H}$ bonds. ${ }^{40,41}$ The peaks at $286.1 \pm 0.45 \mathrm{eV}$ and $289.15 \pm 0.45 \mathrm{eV}$ were attributed respectively to $\mathrm{C}-\mathrm{O}$ and $\mathrm{O}=\mathrm{C}-\mathrm{O}$ bonds. ${ }^{40}$ For the $\mathrm{TiO}_{2}$ -PEG3350 nanocomposite, the peak at $289.15 \pm 0.45 \mathrm{eV}$ is not present. For the $\mathrm{TiO}_{2}-\mathrm{Dopa}, \mathrm{TiO}_{2}-\mathrm{PEG} 3350, \mathrm{TiO}_{2}-\mathrm{PAA}$ and $\mathrm{TiO}_{2-}$ DFOA nanocomposites, a supplementary peak appeared at $287.76 \pm 0.24 \mathrm{eV}$. This peak was attributed to $\mathrm{C}=\mathrm{O}$ bonds. ${ }^{40} \mathrm{On}$ the other hand, previous studies ${ }^{42,43}$ have shown that the peaks at $287.76 \mathrm{eV}$ and $289.15 \mathrm{eV}$ may be from atmospheric contamination. The both peaks at $286.1 \pm 0.45 \mathrm{eV}$ and $287.76 \pm$ $0.24 \mathrm{eV}$ can be originated from the ligands. In the case of pristine $\mathrm{TiO}_{2} \mathrm{NPs}, \mathrm{C}-\mathrm{O}$ bonds could come from a carbon layer surrounding the particles. ${ }^{15}$ The peak at $288.76 \mathrm{eV}$ was only observed for the $\mathrm{TiO}_{2}$-PAA nanocomposite and assigned to -O$\mathrm{C}=\mathrm{O}$ bonds. ${ }^{44-46}$ The titanium Ti2p peak was composed of two main peaks assigned to Ti $2 p_{3 / 2}$ and Ti $2 p_{1 / 2}$ core levels of $\mathrm{Ti}^{4+}$ at $458.97 \pm 0.09 \mathrm{eV}$ and $464.63 \pm 0.17 \mathrm{eV}$, respectively. ${ }^{47,} 48$ The predominant peak at $458.97 \pm 0.09 \mathrm{eV}$ was attributed to $\mathrm{Ti}^{4+}$ ions in $\mathrm{TiO}_{2}{ }_{4}^{48}, 49$ This indicates that these ions are in an octahedral environment, coordinated with oxygen. ${ }^{50,} 51$ XPS spectrum of $\mathrm{TiO}_{2}$-Dopa and $\mathrm{TiO}_{2}$-DFOA nanocomposites show that the Ti $2 p_{3 / 2}$ and Ti $2 p_{1 / 2}$ was shifted toward a lower binding energies compared to pristine $\mathrm{TiO}_{2} \mathrm{NPs}$, approximatively of 0.21 $\mathrm{eV}$ and $0.36 \mathrm{eV}$, respectively. This confirms that the bond between $\mathrm{TiO}_{2}$ and Dopa and DFOA is based on C-O-Ti and not C$\mathrm{Ti}^{52}$ For the $\mathrm{TiO}_{2}$-Dopa nanocomposite, two supplementary peaks appeared at $460.46 \mathrm{eV}$ and $466.04 \mathrm{eV}$, which belong to the $\mathrm{N}-\mathrm{Ti}-\mathrm{O}$ bonds and $\mathrm{C}-\mathrm{O}-\mathrm{Ti}$, respectively. ${ }^{53}$ This $\mathrm{C}-\mathrm{O}-\mathrm{Ti}$ binding in titanium Ti2p compared to pristine $\mathrm{TiO}_{2}$ NPs was attributed to covalent interaction of the ligand with $\mathrm{Ti}$ sites at the surface. The new peak in titanium Ti2p corresponding to $\mathrm{N}-\mathrm{Ti}-\mathrm{O}$ suggest an electrostatic interaction between the positively charged $\mathrm{NH}_{3}{ }^{+}$groups in the ligands with $\mathrm{O}^{2-}$ sites at the surface. The grafting of Dopa on the $\mathrm{TiO}_{2}$ NPs surface could be the result of a combination of covalent interaction (C-O-Ti bonds) and electrostatic interaction via protonated $\mathrm{NH}_{2}$ at the surface whereas the grafting of DFOA on the $\mathrm{TiO}_{2}$ NPs surface is purely covalent. The binding energies are now $457.48 \mathrm{eV}$ and 462.92 eV were attributed to Ti $2 p_{3 / 2}$ and Ti $2 p_{1 / 2}$ of $\mathrm{Ti}^{3+} .54,55$ This means that the $\mathrm{Ti}^{3+}$ sites were created in nanocomposites during the grafting. This oxidation of Ti sites at the surface could be due to absorption of the DFOA on the $\mathrm{TiO}_{2}$ surface. The deconvolution of the $01 \mathrm{~s}$ spectrum shows a main peak at $530.30 \pm 0.13 \mathrm{eV}$ attributed to oxygen atoms of $\mathrm{TiO}_{2}$ lattice and various minor peaks at higher binding energies. ${ }^{56}$ The minor peaks at $531.33 \pm$ $0.04 \mathrm{eV}$ and $533.09 \pm 0.09 \mathrm{eV}$ were assigned respectively to $\mathrm{OH}$ and $\mathrm{H}_{2} \mathrm{O}$ species, indicating the presence of hydrated oxides at the $\mathrm{TiO}_{2}$ surface. ${ }^{57}$ For the $\mathrm{TiO}_{2}$-PEG3350 and $\mathrm{TiO}_{2}$-PAA nanocomposites, new bonds appeared compared to XPS spectra of pristine $\mathrm{TiO}_{2}$ NPs. A slight shift of the peak at $531.33 \pm 0.04 \mathrm{eV}$ is observed for $\mathrm{TiO}_{2}-\mathrm{PEG} 3350$ and $\mathrm{TiO}_{2}-\mathrm{PAA}$ nanocomposites, of approximately $0.25 \mathrm{eV}$, probably due to the adhesion of the ligands. The peak at $533.09 \pm 0.09 \mathrm{eV}$ was not observed for the pristine $\mathrm{TiO}_{2}$ NPs and $\mathrm{TiO}_{2}$-PAA nanocomposite. However, for pristine $\mathrm{TiO}_{2} \mathrm{NPs}$, a peak at $532.47 \mathrm{eV}$ appears. This peak can be assigned to $\mathrm{C}-\mathrm{O}$ bonds 52 which comes from a carbon layer coating surrounding the particles. B.F. Xin et al. ${ }^{58}$ suggest that the peaks at binding energy at 531-533 eV can be attributed to oxygen chemisorbed such as $\mathrm{O}_{2},-\mathrm{OH}$, and $-\mathrm{CO}_{3}$ on $\mathrm{TiO}_{2}$ surfaces. Moreover, the peak at binding energy at $533.87 \mathrm{eV}$ can be assigned to the oxygen atoms connected to carbon atoms in C-O.59 This suggests that the grafting with the polymers is a non-covalent grafting occurring preferentially on $\mathrm{O}$ sites at the $\mathrm{TiO}_{2}$ surface. The concentration of each elements related to the nanocomposites were also determined by XPS. Table S2 presents the average chemical composition measured over each sample. The pristine $\mathrm{TiO}_{2}$ NPs contain 8.30 at\% of carbon, which is coming from a thin carbon layer contamination surrounding the particles. This result is in agreement to thermogravimetric measurements. For the $\mathrm{TiO}_{2}$-Dopa, $\mathrm{TiO}_{2}-\mathrm{PEG} 3350, \mathrm{TiO}_{2}$-PAA and $\mathrm{TiO}_{2}$-DFOA nanocomposites, the carbon concentration is about 2.6 times higher than for pristine $\mathrm{TiO}_{2}$ NPs. This indicates that the carbon finds its origins from the ligands. Elements such as F, N, P and $\mathrm{Na}$ were also present in our spectra and represent a total of 3 at\%. 
C1s

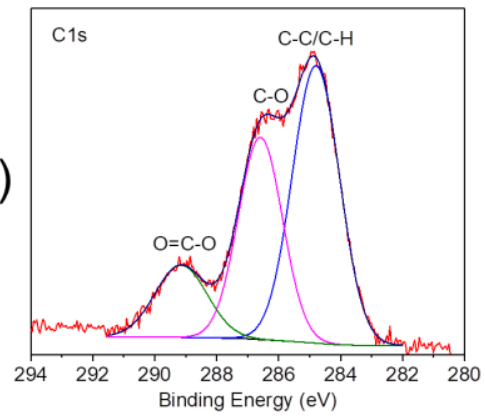

(b)

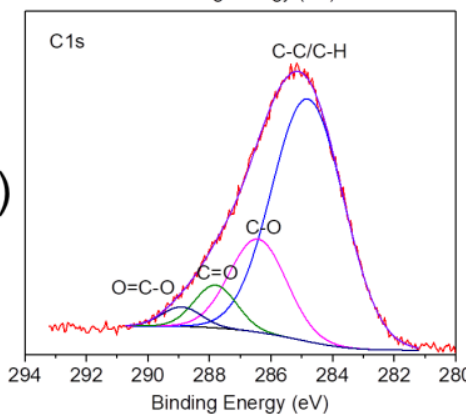

(c)
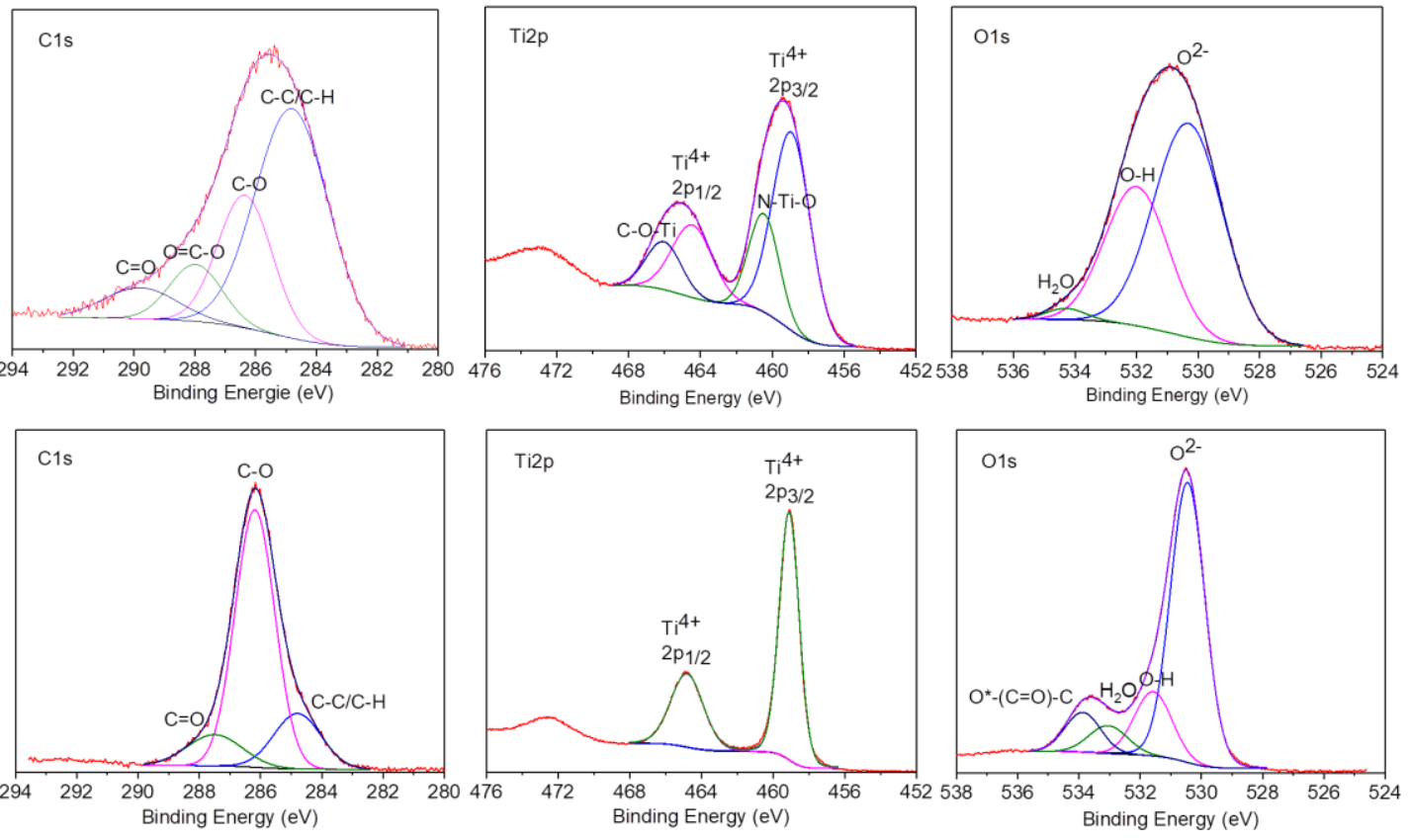

(d)
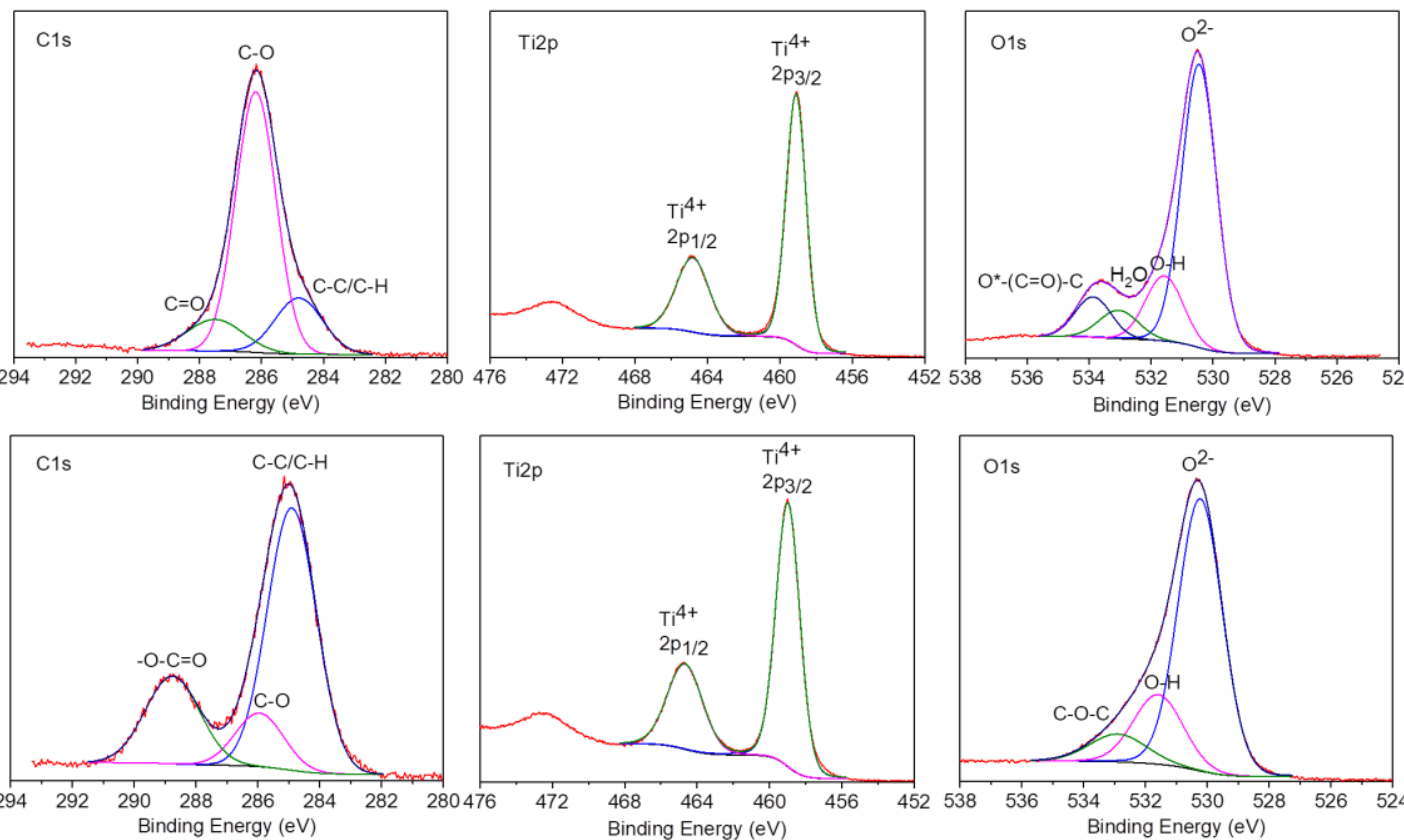

Fig. 5: XPS spectra of pristine $\mathrm{TiO}_{2} \mathrm{NPs}$ and $\mathrm{TiO}_{2} \mathrm{NPs}$ coated with bio-inspired ligand. $\mathrm{C} 1 \mathrm{~s}, \mathrm{Ti} 2 \mathrm{p}$ and $\mathrm{O} 1 \mathrm{~s}$ spectra of (a) pristine TiO 2 NPs, TiO $\mathrm{NPs}_{2}$ coated with (b) Fig. 5: XPS spectra of pristine $\mathrm{TiO}_{2} \mathrm{NPs}^{2}$ and $\mathrm{TiO}_{2} \mathrm{NPs}$ coate
deferoxamine (DFOA), (c) Dopa, (d) PEG3350 and (e) PAA. 
Coating rate of the $\mathrm{TiO}_{2} \mathrm{NPs}$.

Taking into account the molar amount of active sites available (O and/or Ti) deduced from Jankovic et al. ${ }^{60}$ formula for an anatase spherical particles (Text S1), the grafting mode on the surface from the XPS study (covalently and/or electrostatically via $\mathrm{Ti}$ and/or $\mathrm{O}$ sites, respectively), the denticity of the ligand and the amount of coating present on the surface extracted from TGA, one can estimate the particle coating rate for the different ligands (Table 3 ). Variability among the nanocomposites was observed depending on the chemical nature of the ligand (molecular weight, grafting mode, denticity) and its affinity with the $\mathrm{TiO}_{2}$ surface. The highest coating rate in the case of bio-molecules and polymers was found respectively with Dopa ( $24.3 \%$ of active sites coated) and PEG10000 (coated surface of approximately 42.6\%). Among the molecular coatings, Dopa has a highest binding affinity with the $\mathrm{TiO}_{2}$ surface than Lysine (12.56\%) and DFOA (5.25\%). The covalent grafting mechanism offers a fewest available sites for the adhesion of the ligand (reaction with the titanium sites only) compared to non-covalent grafting (multiple van der Waalstype interactions with the $\mathrm{Ti}$ and $\mathrm{O}$ sites but also hydrogens bonding with the hydroxyl layer). However, this estimation takes only into account the ideal case where the nanoparticles are perfectly dispersed in solution (primary $\mathrm{TiO}_{2} \mathrm{NPs}$ with a diameter of $4 \mathrm{~nm}$ ). Indeed, DLS measurements of the nanocomposites (Fig. S3) rather indicated the presence of clusters of particles of a $100 \mathrm{~nm}$ radius decreasing drastically the number of available surface sites for the adsorption/exchange reaction with hydroxyl groups to take place. (a)

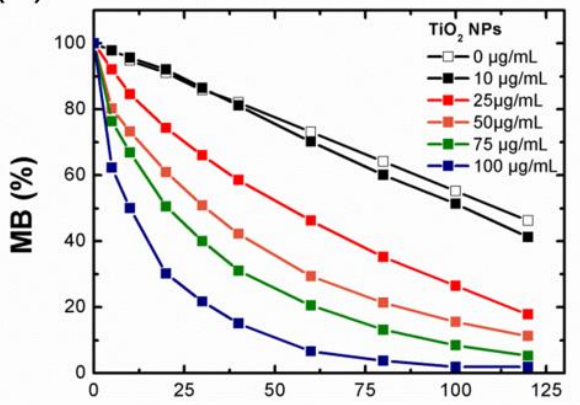

(b)

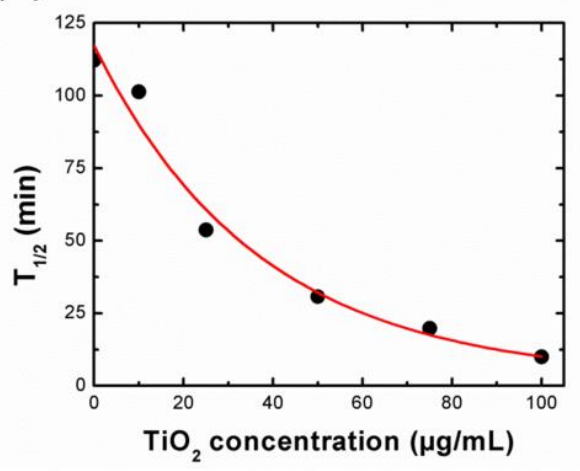

Fig. 6: Photocatalytic activity of the $\mathrm{TiO}_{2} \mathrm{NPs}$ in water (pH 7.0). (a) Degradation of $\mathrm{MB}$ under UV-vis irradiation as a function of the $\mathrm{TiO}_{2} \mathrm{NPs}$ concentration. (b) Halfdegradation time of $\mathrm{MB}$ (time necessary to deteriorate $50 \%$ of $\mathrm{MB}$ ) as a function of the $\mathrm{TiO}_{2} \mathrm{NPs}$ concentration. $\mathrm{MB}(\%)=\left(\left(\mathrm{A}_{665 \mathrm{~nm}, \mathrm{t}}-\mathrm{A}_{665 \mathrm{~nm}, \mathrm{t}}\right) / \mathrm{A}_{665 \mathrm{~nm}, \mathrm{t} 0}\right) \times 100$

Table 3: Composition of the $\mathrm{TiO}_{2}$ nanocomposites (water, $\mathrm{TiO}_{2}$, coating) for $100 \mathrm{mg}$ of powder according to TGA and estimation of the coating rate of one particle.

\begin{tabular}{|c|c|c|c|c|c|c|c|c|}
\hline Nanocomposite & $\begin{array}{c}M_{\text {ligand }} \\
(\text { g.mol } \\
\text {-1) }\end{array}$ & n denticity & $\begin{array}{l}\mathrm{H}_{2} \mathrm{O} \\
(\mathrm{mg})\end{array}$ & $\begin{array}{l}\mathrm{TiO}_{2} \\
\text { (mg) }\end{array}$ & $\begin{array}{c}\text { Coating } \\
\text { (mg) }\end{array}$ & $\begin{array}{c}\mathrm{TiO}_{2} \text { adsorption } \\
\text { sites }^{\alpha}\end{array}$ & $\begin{array}{c}\text { Coating (theory) } \\
(\mathrm{mg})^{\beta}\end{array}$ & $\begin{array}{c}\text { Coating } \\
\text { rate }(\%)^{\gamma}\end{array}$ \\
\hline $\mathrm{TiO}_{2}$-Lysine & 146 & 1 & 10.5 & 83.5 & 6.0 & $\mathrm{Ti}$ & 47.8 & 12.6 \\
\hline $\mathrm{TiO}_{2}-\mathrm{DFOA}$ & 656.8 & 1 & 6.6 & 82.3 & 11.1 & $\mathrm{Ti}$ & 211.5 & 5.2 \\
\hline $\mathrm{TiO}_{2}$-Dopa & 197.2 & 1 & 4.4 & 80.5 & 15.1 & $\mathrm{Ti}$ & 62.1 & 24.3 \\
\hline $\mathrm{TiO}_{2}-\mathrm{PEG} 200$ & 200 & 4 & 12.0 & 84.4 & 3.6 & 0 & 33.0 & 10.9 \\
\hline $\mathrm{TiO}_{2}-\mathrm{PEG} 10000$ & 10000 & 178 & 7.4 & 78.0 & 14.6 & $\mathrm{O}$ & 34.3 & 42.6 \\
\hline \multirow[t]{2}{*}{$\mathrm{TiO}_{2}-\mathrm{PAA}$} & 1800 & 25 & 9.7 & 82.4 & 7.9 & $\mathrm{O}$ & 46.4 & 17.0 \\
\hline & & & & & 7.9 & $\mathrm{Ti}+\mathrm{O}$ & 69.6 & 11.3 \\
\hline $\mathrm{TiO}_{2}$-CellTak & 140000 & 1000 & 13.1 & 81.7 & 5.2 & $\mathrm{Ti}$ & 44.8 & 11.6 \\
\hline
\end{tabular}

${ }^{\alpha}$ preferential $\mathrm{TiO}_{2}$ adsorption site based on XPS investigation, ${ }^{\beta}$ theoretical mass of ligand necessary to bind the entire active sites of a $4 \mathrm{~nm}$ spherical anatase particle,

${ }^{v}$ coating rate (CR) calculated according to the formula $\mathrm{CR}=$ (experimental coating mass/theoretical coating mass)*100.

\section{Photocatalytic activity}

Degradation of Methylene Blue (MB) as a function of the $\mathrm{TiO}_{2}$ NPs concentration.

The photocatalytic activities of the $\mathrm{TiO}_{2}$ nanocomposites were evaluated by following the degradation of MB under UV-vis irradiation. The emission spectrum of the lamp can be found in Fig. S6. $\mathrm{TiO}_{2}$ is a wide-bandgap semi-conductor with $3.0-3.2 \mathrm{eV}$ of bandgap energy $(\mathrm{Eg})$ that requires the light excitation with a wavelength range shorter than $400 \mathrm{~nm}$. The photogeneration of electron-hole pairs and reactive radicals $\left(\mathrm{HO}^{*}, \mathrm{O}_{2}{ }^{--}\right)$participates in reduction and oxidation processes at the surface. A first set 
of experiment was conducted by looking at the degradation of $\mathrm{MB}$ as a function of the $\mathrm{TiO}_{2}$ NPs concentration (Fig. 6 and Fig. S7). Fig. 6a presents the degradation of $\mathrm{MB}$ as a function of $\mathrm{TiO}_{2}$ concentration (0-100 $\left.\mu \mathrm{g} \cdot \mathrm{mL}^{-1}\right)$. The results show a linear degradation of $\mathrm{MB}$ under irradiation in the absence of $\mathrm{TiO}_{2}$ with $46 \%$ of the $M B$ degraded after $2 \mathrm{~h}$ of irradiation. However, a faster degradation is clearly observed when $M B$ is irradiated in presence of the $\mathrm{TiO}_{2}$ NPs. This photolysis is considerably accelerated when increasing the $\mathrm{TiO}_{2} \mathrm{NPs}$ concentration. Fig. $6 \mathrm{~b}$ represents the half-degradation time of $\mathrm{MB}\left(\mathrm{t}_{1 / 2}\right.$, time necessary for degrading $50 \%$ of $\mathrm{MB}$ under irradiation) as a function of the $\mathrm{TiO}_{2}$ NPs concentration. The recorded points fit well with an exponential fitting. Therefore, $50 \%$ of the $M B$ is completely degraded after $100 \mathrm{~min}$ of irradiation at a concentration of 10 $\mu \mathrm{g} \cdot \mathrm{mL}^{-1}$. This time decrease down to $10 \mathrm{~min}$ at a concentration of $100 \mu \mathrm{g} \cdot \mathrm{mL}^{-1}$.

\section{Influence of the coating on the photo-catalytic activity.}

This first series of experiments showed that the photocatalytic activity is highly sensitive to the $\mathrm{TiO}_{2}$ concentration. For the following experiments, we fixed a $\mathrm{TiO}_{2} \mathrm{NPs}$ concentration of 50 $\mu \mathrm{g} . \mathrm{mL}^{-1}$ in order to observe fine changes in the photocatalytic activities. To make sure to get the same $\mathrm{TiO}_{2}$ amount in every sample and compare the photo-catalytic activity of the different nanocomposites, the mass necessary to prepare the $50 \mu \mathrm{g} \cdot \mathrm{mL}^{-1}$ solutions was weighted according to the $\mathrm{TiO}_{2}$ wt\% content found by TGA. Because the photocatalytic activity is strongly influenced by the $\mathrm{pH},{ }^{61}$ the activities of $\mathrm{TiO}_{2} \mathrm{NPs}$ coated with bio-inspired ligands (Fig. 7) were evaluated at $\mathrm{pH}$ 7.0. Fig. 7a and Fig. $7 \mathrm{~b}$ show the degradation of MB under UV-vis irradiation in presence of the nanocomposites in the case of the biomolecular and bio-polymeric coatings, respectively (Fig. S8). The superimposition for all coatings can be found in Fig. S9 and the photocatalytic activity $\left(\mathrm{T}_{1 / 2}\right)$ compared to the pristine $\mathrm{TiO}_{2} \mathrm{NPs}$ is reported in Table 1 . The dataset nicely shows a good modulation of the photo-catalytic activity with the different coatings surrounding the $\mathrm{TiO}_{2}$ NPs. For the bio-molecule coatings (Fig. 7a), the photo-catalytic activity is slightly reduced with Lysine and DFOA coatings. However, the photo-catalytic activity is strongly decreased when the $\mathrm{TiO}_{2} \mathrm{NPs}$ are coated with Dopa that possesses a stronger binding affinity toward the $\mathrm{TiO}_{2}$ surface and a higher coating rate compared to Lysine and DFOA. Two regimes can clearly be observed: a slow degradation of $M B$ between 0 and 40 min followed by a more rapid degradation with a progressive increase of the standard deviations. This suggests a deterioration of the Dopa coating over time as its photodegradation by $\mathrm{TiO}_{2}$ have already been observed in aqueous media. ${ }^{62}$ In the case of bio-polymers (Fig. 7b), the coating of the $\mathrm{TiO}_{2}$ NPs with PEG of different molecular weights shows different behaviors. The photocatalytic activity is less impacted with PEG200 (-21\%) and PEG10000 (-33\%) contrary to PEG3350 coating where a decrease of the activity by around $80 \%$ was found. PEG200, PEG3350 and PEG1000 have an increasing coating rate according to the TGA calculations (Table $3)$, which can be directly correlated to the thickness of the polymeric layer on the surface. Based on these results, we can assume that the photocatalytic activity is influenced by the thickness of the polymeric layer coating, but further investigations are needed to ascertain this hypothesis. A strong decrease was also observed for the CellTak ${ }^{\circledR}$ poly-dopamine with possible deterioration of the coating as the same behavior than Dopa can be noticed (two distinct regimes with a more intense degradation and progressive increase of the standard deviation over time). Contrary to Dopa and the polyDopa, PEG3350 coating seems to be more stable over the irradiation cycle. Interestingly, the $\mathrm{TiO}_{2}$-PAA nanocomposite is the only coating exhibiting an increase of the photocatalytic activity by around $20 \%$.

The photocatalytic activity seems very sensitive to a change at the surface of the $\mathrm{TiO}_{2}$ nanoparticles. It was shown that the activity depends on both intrinsic $\mathrm{TiO}_{2}$ NPs properties (crystallinity, surface charge, particle size, presence of defect sites) and interfacial interactions with the substrate. ${ }^{63}$ As the intrinsic TiO2 NP properties and experimental conditions $(\mathrm{pH}$, concentration) were kept identical in the different experiments, the decrease can be explained by a less surface available for the adsorption/degradation reaction of $\mathrm{MB}$ to take place because of the surface coverage by the ligand.

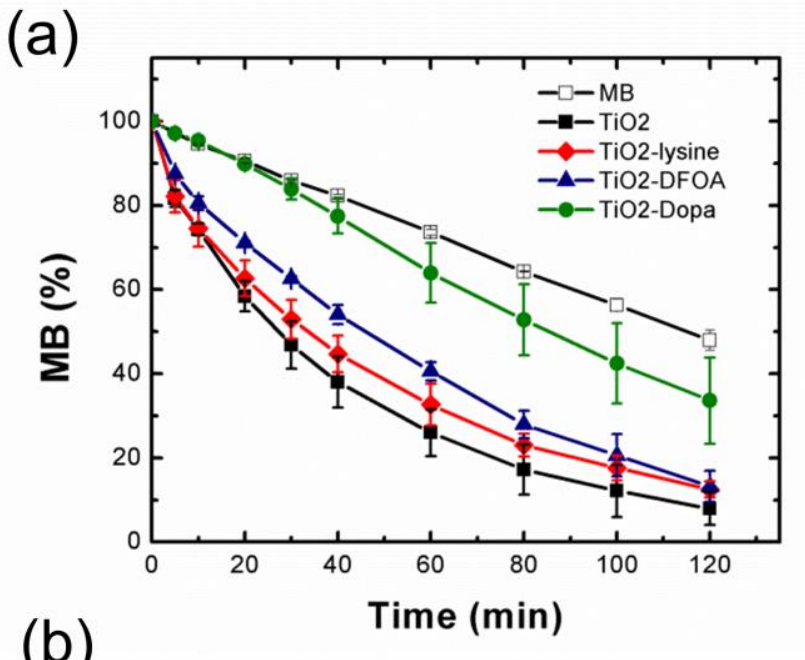

(b)

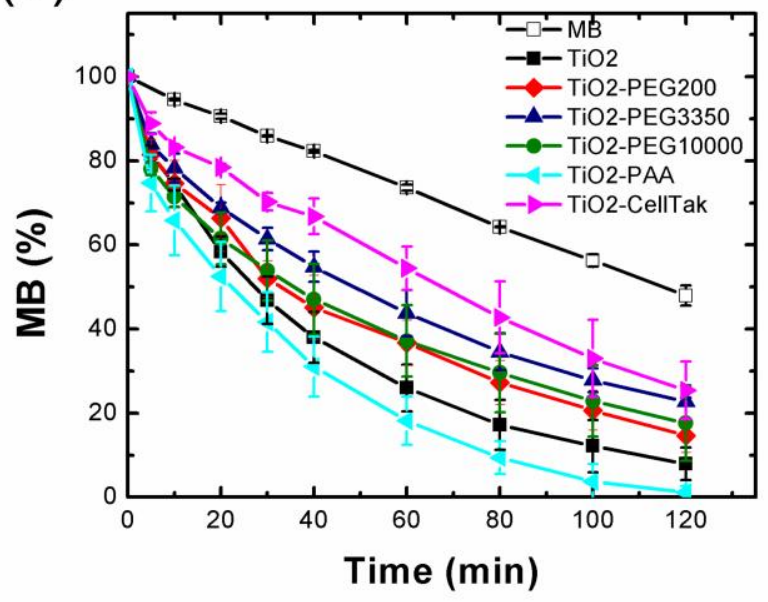

Fig. 7: Influence of the coating on the photo-catalytic activity. Degradation of $\mathrm{MB}$ under UV-vis irradiation with $\mathrm{TiO}_{2} \mathrm{NPs}\left(50 \mu \mathrm{g} \cdot \mathrm{mL}^{-1}\right)$ coated with (a) biomolecules and $(b)$ biopolymers. $M B(\%)=\left(\left(A_{665 n m, t}-A_{665 n m}, t 0\right) / A_{665 n m}, t 0\right) \times 100$. Error bars determined from duplicate experiments. 
prepare under mild conditions (e.g., without use of toxic solvents).

Concerning the increase of the photocatalytic activity observed with PAA, the proximity of the polymer energy levels $64-$ with a HOMO (highest occupied molecular orbital) and LUMO (lower unoccupied molecular orbital) located respectively at $-7.6 \mathrm{eV}$ and $-4.0 \mathrm{eV}-$ and the valence $\left(\mathrm{E}_{\mathrm{vb}}\right)$ /conduction $\left(\mathrm{E}_{\mathrm{cb}}\right)$ bands of anatase $\mathrm{TiO}_{2}\left(E_{\mathrm{vb}}=-7.1 \mathrm{eV} ; \mathrm{E}_{\mathrm{cb}}=-3.95 \mathrm{eV}\right){ }^{65}$ could favor the formation of a type II heterojunction between the polymer and the nanoparticles. Recently, Liu et al. ${ }^{66}$ reported a so-called "Lock-in Effect" in a heterojunction of a $\mathrm{COOH}$ conjugated polymer and $\mathrm{TiO}_{2}$ exhibiting outstanding photocatalytic activity. These new electronic properties resulted from the interfacial interaction between the carboxyl (also present in PAA) and hydroxyl groups of $\mathrm{TiO}_{2}$, improving drastically the electron-hole separation efficiency and the interface charge transfer ability.

\section{Paint formulation with $\mathrm{TiO}_{2}$ NPs coated with bio-inspired ligands.}

Finally, paints were formulated with different photocatalytic $\mathrm{TiO}_{2}$ nanocomposites chosen according to their stability and photocatalytic activity (Table 1 ). Based on these criteria, uncoated $\mathrm{TiO}_{2}$ (control), $\mathrm{TiO}_{2}$-Dopa (high colloidal stability, $215 \%$ decrease of the photocatalytic activity), $\mathrm{TiO}_{2}-\mathrm{PEG} 3350$ (high colloidal stability, $-80 \%$ decrease of the photocatalytic activity) and $\mathrm{TiO}_{2}$-PAA (high colloidal stability, $+20 \%$ increase of the photocatalytic activity) NPs were selected and incorporated in paints at a $3.5 \mathrm{wt} \% \mathrm{TiO}_{2}$ content. After deposition on Leneta substrates, the paints were aged for one year in the dark or under interior day light (Fig. 8a). Whereas the paints exhibits a stable bright white coloration, the $\mathrm{TiO}_{2}$-Dopa formulated paint possesses a characteristic brown color due to LMCT band issued from the covalent binding between Dopa and Ti sites on the $\mathrm{TiO}_{2}$ NPs surface. This paint progressively turned to white after ageing in day light. This change of color can be associated to the progressive photodegradation of the Dopa coating by $\mathrm{TiO}_{2}$ as suggested by the photocatalytic activity of the NPs and reported in the literature. ${ }^{62}$

Chalking assays performed after one year of storage (Fig. 8b) showed a high amount of collected powder on the tape with the $\mathrm{TiO}_{2}$-PAA nanocomposites formulated paint (quotation of 5 and 4 after ageing in the dark and day light, respectively). This observation lets suggest a more intense degradation of the mechanical strength of the paint with this coating. Hence, it comes to confirm the enhanced photocatalytic activity exhibited by these NPs (+20\%) compared to the original $\mathrm{TiO}_{2}$ nanopowder. A decrease of the $\mathrm{TiO}_{2}$ NP content by $20 \%$ could eventually be applied during the formulation to reduce the paint degradation and observe a comparable photocatalytic effect of the paint The quotation of the $\mathrm{TiO}_{2}$-Dopa paint after ageing in day light (quotation of 4) strongly increased compared to the aged in the dark and the $\mathrm{TiO}_{2}$ control ones (quotations of 2 ), which could be the direct consequence of the degradation of the coating under irradiation as mentioned above. Among the three selected coatings, PEG3350 is the most promising one since the formulated paint appeared to be the most stable after ageing. This polymer is also relatively inexpensive and the NPs easy to

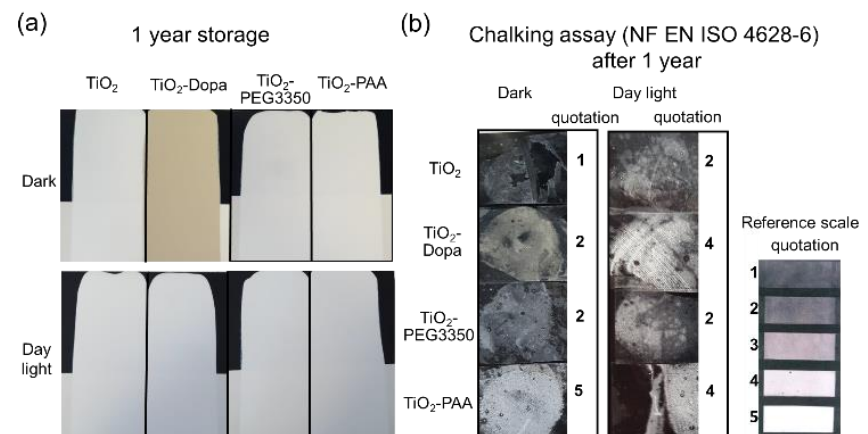

Fig. 8:(a) photographies of paints deposited on Leneta substrats after storage in dark and exposed to day light.and (b) chalking assay after storage for one year in dark or under interior day light of paints formulated with photocatalytic $\mathrm{TiO}_{2} \mathrm{NPs}$ uncoated or coated with Dopa, PEG3350 and PAA.

\section{Conclusions}

We successfully modified the surface of a commercial photocatalytic $\mathrm{TiO}_{2}$ nanopowder with bio-inspired ligands of different chemical nature (molecules and polymers) for its application in self-cleaning paint. The coating strategy relied on the electrostatic stabilization in aqueous media with a pyrophosphate buffer (acid or basic conditions) followed by the addition of the ligand providing an extra steric stability compared to the initial particles.

The grafting and quantification of the ligand on the surface were confirmed by FTIR spectroscopy and TGA analysis performed on the nanocomposites. The grafting mode of several ligands was investigated by XPS and showed that the binding resulted from a combination of covalent and electrostatic interactions depending on the ligand chemical nature and architecture. These nanocomposites exhibit variable photocatalytic activities based on the degradation of MB under UV-vis irradiation, meeting our initial objective toward the safer-by-design development of a self-cleaning paint. As most of the ligands decreased more or less strongly the photocatalytic activity of the $\mathrm{TiO}_{2} \mathrm{NPs}$, the nanocomposites should induce fewer damages to mechanical strength of the paint once incorporated in the paints while keeping the self-cleaning property. Only the coating with PAA presented an increase of the photocatalytic activity. With this feature, fewer particles in number would be necessary in the paint formulation for observing the same selfcleaning effect, and concomitantly, a lower amount of NPs would be released by mechanical stress, use or ageing over the paint life cycle. In order to improve the performance of the nanocomposites, the influence of the coating rate (thickness of the coating) on the photocatalytic properties, its resistance over several irradiation cycles and ageing would need to be investigated. The performance of these safer-by-design photocatalytic paints during their life cycle (photocatalytic efficiency, NPs emission during use, abrasion and incineration, 
NPs toxicity and genotoxicity) should be further analyzed to evaluate their environmental benefits. Actually, the NPs and VOCs released during the use, weathering and mechanical solicitation of the formulated paints have been already further investigated and will be published in a separate paper. ${ }^{20}$ It confirms the interest of our nanocomposites and our safer-bydesign approach.

\section{Conflicts of interest}

There are no conflicts to declare.

\section{Acknowledgements}

The authors acknowledge Stéphane Ménage and Aurélien Deniaud for interesting discussions. This work is a contribution to the LABEX SERENADE ( $n^{\circ}$ ANR-11-LABX-0064) funded by the "Investissements d'Avenir" French Government program of the French National Research Agency (ANR) through the A*MIDEX project ( $N^{\circ}$ ANR-11-IDEX-0001-02). This research is part of the LabEx ARCANE and CBH-EURGS (grant ANR-17-EURE-0003). JL and $A R$ were supported by the SafeTiPaint project granted by the LabEx SERENADE. The NanoZS were funded by the EQUIPEX NanoID (grant ANR-10-EQPX-39-01).

\section{Abbreviation}

$\mathrm{TiO}_{2}$ NPs: Titanium dioxide nanoparticles; DFOA: Deferoxamine; Dopa: Dopamine; PAA: Poly-acrylic acid; PEG: Polyethylene glycol; $\mathrm{MB}$ : Methylene blue; $\mathrm{H}_{2}$ Pyro and NaPyro: acidic $\left(\mathrm{Na}_{2} \mathrm{H}_{2} \mathrm{P}_{2} \mathrm{O}_{7}, \mathrm{pH} 4.5\right)$ and alkaline forms $\left(\mathrm{Na}_{4} \mathrm{P}_{2} \mathrm{O}_{7}, \mathrm{pH}\right.$ 8.5) of pyrophosphate, respectively; FTIR: Fourrier-transformed infrared; SEM: Scanning electron micrography; EDX: Energydispersive X-ray spectroscopy.

\section{References}

1. J. Jeevanandam, A. Barhoum, Y. S. Chan, A. Dufresne and M. K. Danquah, Review on nanoparticles and nanostructured materials: history, sources, toxicity and regulations, Beilstein J. Nanotechnol., 2018, 9, 1050-1074.

2. M. Usman, M. Farooq, A. Wakeel, A. Nawaz, S. A. Cheema, H. u. Rehman, I. Ashraf and M. Sanaullah, Nanotechnology in agriculture: Current status, challenges and future opportunities, Sci. Tot. Environ., 2020, 721, 137778.

3. S. D. F. Mihindukulasuriya and L. T. Lim, Nanotechnology development in food packaging: A review, Trends Food Sci. Technol., 2014, 40, 149-167.

4. L. Kaounides, H. Yu and T. Harper, Nanotechnology innovation and applications in textiles industry: current markets and future growth trends, Mater. Technol., 2007, 22, 209-237.

5. V. Kostopoulos, A. Masouras, A. Baltopoulos, A. Vavouliotis, G. Sotiriadis and L. Pambaguian, A critical review of nanotechnologies for composite aerospace structures, CEAS Space J., 2017, 9, 35-57.
6. O. M. Koo, I. Rubinstein and H. Onyuksel, Role of nanotechnology in targeted drug delivery and imaging: a concise review, Nanomedicine, 2005, 1, 193-212.

7. M. T. Alsaba, M. F. Al Dushaishi and A. K. Abbas, A comprehensive review of nanoparticles applications in the oil and gas industry, J. Petrol. Explor. Prod. Technol., 2020, 10, 1389-1399.

8. The Nanodatabase, http://www.nanodb.dk .

9. S. Foss Hansen, L. R. Heggelund, P. Revilla Besora, A. Mackevica, A. Boldrin and A. Baun, Nanoproducts - what is actually available to European consumers?, Environ. Sci. Nano, 2016, 3, 169-180.

10. J.-P. Kaiser, S. Zuin and P. Wick, Is nanotechnology revolutionizing the paint and lacquer industry? A critical opinion, Sci. Tot. Environ., 2013, 442, 282-289.

11. A. Fujishima, T. N. Rao and D. A. Tryk, Titanium dioxide photocatalysis, J. Photochem. Photobiol. C, 2000, 1, 1-21.

12. X. Chen and S. S. Mao, Titanium Dioxide Nanomaterials: Synthesis, Properties, Modifications, and Applications, Chem. Rev., 2007, 107, 2891-2959.

13. A. Gandolfo, L. Rouyer, H. Wortham and S. Gligorovski, The influence of wall temperature on $\mathrm{NO}_{2}$ removal and $\mathrm{HONO}$ levels released by indoor photocatalytic paints, Appl. Catal. B, 2017, 209, 429-436.

14. B. Fiorentino, L. Golanski, A. Guiot, J. F. Damlencourt and D. Boutry, Influence of paints formulations on nanoparticles release during their life cycle, J. Nanopart. Res., 2015, 17.

15. D. Truffier-Boutry, B. Fiorentino, V. Bartolomei, R. Soulas, O. Sicardy, A. Benayad, J. F. Damlencourt, B. Pepin-Donat, C. Lombard, A. Gandolfo, H. Wortham, G. Brochard, A. Audemard, L. Porcar, G. Gebel and S. Gligorovski, Characterization of photocatalytic paints: a relationship between the photocatalytic properties - release of nanoparticles and volatile organic compounds, Environ. Sci. Nano, 2017, 4, 1998-2009.

16. A. T. Saber, K. A. Jensen, N. R. Jacobsen, R. Birkedal, L. Mikkelsen, P. Moller, S. Loft, H. Wallin and U. Vogel, Inflammatory and genotoxic effects of nanoparticles designed for inclusion in paints and lacquers, Nanotoxicology, 2012, 6, 453-471.

17. S. Lin, T. Yu, Z. Yu, X. Hu and D. Yin, Nanomaterials safer-bydesign: an environmental safety perspective, Adv. Mater., 2018, 30, 1705691.

18. J. Y. Bottero, J. Rose, C. de Garidel, A. Masion, T. Deutsch, G. Brochard, M. Carriere, N. Gontard, H. Wortham, T. Rabilloud, B. Salles, M. Dubosson, B. Cathala, D. Boutry, A. Ereskovsky, C. Auplat, L. Charlet, T. Heulin, E. Frejafon and S. Lanone, SERENADE: safer and ecodesign research and education applied to nanomaterial development, the new generation of materials safer by design, Environ. Sci-Nano, 2017, 4, 526-538.

19. H. Park, Y. Park, W. Kim and W. Choi, Surface modification of $\mathrm{TiO} 2$ photocatalyst for environmental applications, $J$. Photochem. Photobiol. C, 2013, 15, 1-20.

20. A. Rosset, V. Bartolomei, J. Laisney, N. Shandilya, H. Voisin, J. Morin, I. Michaud-Soret, I. Capron, H. Wortham, G. Brochard, V. Bergé, M. Carriere, F. Dussert, O. Le Bihan, C. Dutouquet, D. Truffier-Boutry, S. Clavaguera, S. Artous, Towards the 
development of Safer by Design $\mathrm{TiO}_{2}$-based photocatalytic paint: impacts and performances, Environ. Sci.: Nano, 2020, Submitted.

21. I. A. Jankovic, Z. V. Saponjic, E. S. Dzunuzovic and J. M. Nedeljkovic, New Hybrid Properties of $\mathrm{TiO}_{2}$ Nanoparticles Surface Modified With Catecholate Type Ligands, Nanoscale Res. Lett., 2010, 5, 81-88.

22. J. Yu, W. Wei, M. S. Menyo, A. Masic, J. H. Waite and J. N. Israelachvili, Adhesion of Mussel Foot Protein-3 to $\mathrm{TiO}_{2}$ Surfaces: the Effect of pH, Biomacromolecules, 2013, 14, 1072-1077.

23. J. Manson, D. Kumar, B. J. Meenan and D. Dixon, Polyethylene glycol functionalized gold nanoparticles: the influence of capping density on stability in various media (vol 44, pg 99, 2011), Gold Bull., 2011, 44, 195-196.

24. J. B. Luo, S. X. Qiu, X. Y. Zhou, R. H. Lai, P. J. Dong and X. Y. Xie, In situ grafting polyethylene glycol chains onto amorphous calcium phosphate nanoparticles to improve the storage stability and organic solvent redispersibility, Colloid Surf. $A$ 2014, 444, 81-88.

25. E. Harrison, J. R. Nicol, M. Macias-Montero, G. A. Burke, J. A. Coulter, B. J. Meenan and D. Dixon, A comparison of gold nanoparticle surface co-functionalization approaches using Polyethylene Glycol (PEG) and the effect on stability, nonspecific protein adsorption and internalization, Mat. Sci. Eng. C-Mater, 2016, 62, 710-718.

26. J. Eisenlauer, E. Killmann and M. Korn, Stability of Colloidal Silica (Aerosil) Hydrosols .2. Influence of the Ph Value and the Adsorption of Polyethylene Glycols, J. Colloid. Interf. Sci. 1980, 74, 120-135.

27. S. C. Liufu, H. N. Xiao, Y. P. Li and Z. R. Hu, Polyethylene glycol adsorption behavior on nanoparticulate $\mathrm{TiO}_{2}$ and its stability in aqueous dispersions, J. Inorg. Mater., 2005, 20, 310-316.

28. H. B. Na, G. Palui, J. T. Rosenberg, X. Ji, S. C. Grant and H. Mattoussi, Multidentate Catechol-Based Polyethylene Glycol Oligomers Provide Enhanced Stability and Biocompatibility to Iron Oxide Nanoparticies, Acs Nano, 2012, 6, 389-399.

29. M. F. Tai, C. W. Lai and S. B. A. Hamid, Facile Synthesis Polyethylene Glycol Coated Magnetite Nanoparticles for High Colloidal Stability, J. Nanomater., 2016, DOI: 10.1155/2016/8612505.

30. T. J. Deming, Mussel byssus and biomolecular materials, Curr. Opin. Chem. Biol., 1999, 3, 100-105.

31. G. P. Maier and A. Butler, Siderophores and mussel foot proteins: the role of catechol, cations, and metal coordination in surface adhesion, J. Biol. Inorg. Chem., 2017, 22, 739-749.

32. G. P. Maier, M. V. Rapp, J. H. Waite, J. N. Israelachvili and A. Butler, BIOLOGICAL ADHESIVES. Adaptive synergy between catechol and lysine promotes wet adhesion by surface salt displacement, Science, 2015, 349, 628-632.

33. J. H. Waite, Mussel glue fromMytilus californianus Conrad: a comparative study, J. Comp. Physiol. B, 1986, 156, 491-496.

34. S. V. Sokolov, K. Tschulik, C. Batchelor-McAuley, K. Jurkschat and R. G. Compton, Reversible or Not? Distinguishing Agglomeration and Aggregation at the Nanoscale, Anal. Chem., 2015, 87, 10033-10039.
35. B. Derjaguin and L. Landau, Theory of the stability of strongly charged lyophobic sols and of the adhesion of strongly charged particles in solutions of electrolytes, Prog. Surf. Sci., 1993, 43, 30-59.

36. M. Wiśniewska, T. Urban, E. Grządka, V. I. Zarko and V. M. Gun'ko, Comparison of adsorption affinity of polyacrylic acid for surfaces of mixed silica-alumina, Colloid. Polym. Sci., 2014, 292, 699-705.

37. W. Wei, J. Yu, C. Broomell, J. N. Israelachvili and J. H. Waite, Hydrophobic Enhancement of Dopa-Mediated Adhesion in a Mussel Foot Protein, J. Am. Chem. Soc., 2013, 135, 377-383.

38. I. A. Jankovic, Z. V. Saponjic, M. I. Comor and J. M. Nedeljlkovic, Surface Modification of Colloidal $\mathrm{TiO}_{2}$ Nanoparticles with Bidentate Benzene Derivatives, J. Phys. Chem. C, 2009, 113, 12645-12652.

39. S. S. Mali, C. A. Betty, P. N. Bhosale and P. S. Patil, Synthesis, Characterization of Hydrothermally Grown MWCNTTiO2Photoelectrodes and Their Visible Light Absorption Properties, ECS J. Solid State Sci. Technol., 2012, 1, M15-M23.

40. V. A. Tran, T. T. Truong, T. A. P. Phan, T. N. Nguyen, T. V. Huynh, A. Agresti, S. Pescetelli, T. K. Le, A. Di Carlo, T. Lund, S.N. Le and P. T. Nguyen, Application of nitrogen-doped $\mathrm{TiO}_{2}$ nano-tubes in dye-sensitized solar cells, Appl. Surf. Sci., 2017, 399, 515-522.

41., High Resolution XPS of Organic Polymers: The Scienta ESCA300 Database (Beamson, G.; Briggs, D.), J. Chem. Educ., 1993, 70, A25.

42. Q. Wang, N. Plylahan, M. V. Shelke, R. R. Devarapalli, M. Li, P. Subramanian, T. Djenizian, R. Boukherroub and S. Szunerits, Nanodiamond particles/reduced graphene oxide composites as efficient supercapacitor electrodes, Carbon, 2014, 68, 175184.

43. F. Zhang, J. Tang, Z. Wang and L.-C. Qin, Graphene-carbon nanotube composite aerogel for selective detection of uric acid, Chem. Phys. Lett., 2013, 590, 121-125.

44. S. Liu, J. Sun and Z. Huang, Carbon spheres/activated carbon composite materials with high $\mathrm{Cr}(\mathrm{VI})$ adsorption capacity prepared by a hydrothermal method, J. Hazard. Mater., 2010, 173, 377-383.

45. W. H. Lee, S. J. Kim, W. J. Lee, J. G. Lee, R. C. Haddon and P. J. Reucroft, X-ray photoelectron spectroscopic studies of surface modified single-walled carbon nanotube material, Appl. Surf. Sci., 2001, 181, 121-127.

46. T. I. T. Okpalugo, P. Papakonstantinou, H. Murphy, J. McLaughlin and N. M. D. Brown, High resolution XPS characterization of chemical functionalised MWCNTs and SWCNTs, Carbon, 2005, 43, 153-161.

47. S. Pan, X. Liu, M. Guo, S. f. Yu, H. Huang, H. Fan and G. Li, Engineering the intermediate band states in amorphous $\mathrm{Ti}^{3+}$ doped $\mathrm{TiO}_{2}$ for hybrid dye-sensitized solar cell applications, $J$. Mater. Chem. A, 2015, 3, 11437-11443.

48. M. C. Biesinger, L. W. M. Lau, A. R. Gerson and R. S. C. Smart, Resolving surface chemical states in XPS analysis of first row transition metals, oxides and hydroxides: $\mathrm{Sc}, \mathrm{Ti}, \mathrm{V}, \mathrm{Cu}$ and $\mathrm{Zn}$, Appl. Surf. Sci., 2010, 257, 887-898.

49. M. G. Faba, D. Gonbeau and G. Pfister-Guillouzo, Core and valence spectra of titanium dichalcogenides $\mathrm{TiX}_{2}$ (where $\mathrm{X}$ is 
O, S). Experimental and theoretical studies, J. Electron Spectros. Relat. Phenomena, 1995, 73, 65-80.

50. D. Zhao, C. Chen, Y. Wang, H. Ji, W. Ma, L. Zang and J. Zhao, Surface Modification of $\mathrm{TiO}_{2}$ by Phosphate: Effect on Photocatalytic Activity and Mechanism Implication, J. Phys. Chem. C, 2008, 112, 5993-6001.

51. K. Raj, R. Shanmugam, R. Mahalakshmi and B. Viswanathan, XPS and IR spectral studies on the structure of phosphate and sulphate modified titania-a combined DFT and experimental study, 2010.

52. P. Georgios and S. M. Wolfgang, X-Ray Photoelectron Spectroscopy of Anatase- $\mathrm{TiO}_{2}$ Coated Carbon Nanotubes, Solid State Phenomena, 2010, 162, 163-177.

53. X. Bai, T. Li, Y.-X. Qi, Y.-X. Wang, L.-W. Yin, H. Li, N. Lun and Y.J. Bai, One-step fabricating nitrogen-doped $\mathrm{TiO}_{2}$ nanoparticles coated with carbon to achieve excellent high-rate lithium storage performance, Electrochim. Acta, 2016, 187, 389-396.

54. H. Ming, J. Ming, X. Li, Q. Zhou, H. Wang, L. Jin, Y. Fu, J. Adkins and J. Zheng, Hierarchical $\mathrm{Li}_{4} \mathrm{Ti}_{5} \mathrm{O}_{12}$ particles co-modified with $\mathrm{C} \& \mathrm{~N}$ towards enhanced performance in lithium-ion battery applications, Electrochim. Acta, 2014, 116, 224-229.

55. R. Gouttebaron, D. Cornelissen, R. Snyders, J. P. Dauchot, M. Wautelet and $\mathrm{M}$. Hecq, XPS study of $\mathrm{TiO}_{\mathrm{x}}$ thin films prepared by d.c. magnetron sputtering in $\mathrm{Ar}-\mathrm{O} 2$ gas mixtures, Surf. Interface Anal., 2000, 30, 527-530.

56. N. C. Saha and H. G. Tompkins, Titanium nitride oxidation chemistry: An x-ray photoelectron spectroscopy study, J. Appl. Phys., 1992, 72, 3072-3079.

57. L. Avalle, E. Santos, E. Leiva and V. A. Macagno, Characterization of $\mathrm{TiO}_{2}$ films modified by platinum doping, Thin Solid Films, 1992, 219, 7-17.

58. B. Xin, P. Wang, D. Ding, J. Liu, Z. Ren and H. Fu, Effect of surface species on $\mathrm{Cu}-\mathrm{TiO}_{2}$ photocatalytic activity, Appl. Surf. Sci., 2008, 254, 2569-2574.

59. H. Liu, J. Liu, W. Song, F. Wang and Y. Song, $\mathrm{Li}_{\mathrm{x}} \mathrm{Co}_{3}-\mathrm{XO}_{4}$ solid solution nanocrystals supported on carbon black as a superior electrocatalyst for oxygen reduction reaction, Mater. Lett., 2015, 139, 447-450.

60. I. A. Jankovic, Z. V. Saponjic, M. I. Comor and J. M. Nedeljkovic, Surface modification of colloidal $\mathrm{TiO}_{2}$ nanoparticles with bidentate benzene derivatives, J. Phys. Chem. C, 2009, 113, 12645-12652.

61. Nasikhudin, M. Diantoro, A. Kusumaatmaja and K. Triyana, Study on Photocatalytic Properties of $\mathrm{TiO}_{2}$ Nanoparticle in various pH condition, J. Phys. Conf. Ser., 2018, 1011, 012069.

62. A. L. Chibac, T. Buruiana, V. Melinte and E. C. Buruiana, Photocatalysis applications of some hybrid polymeric composites incorporating $\mathrm{TiO}_{2}$ nanoparticles and their combinations with $\mathrm{SiO}_{2} / \mathrm{Fe}_{2} \mathrm{O}_{3}$, Beilstein J. Nanotechnol., 2017, 8, 272-286.

63. Y. Nam, J. H. Lim, K. C. Ko and J. Y. Lee, Photocatalytic activity of TiO2 nanoparticles: a theoretical aspect, J. Mater. Chem. A, 2019, 7, 13833-13859.

64. Y. Zhu, A. Apostoluk, P. Gautier, A. Valette, L. Omar, T. Cornier, J. M. Bluet, K. Masenelli-Varlot, S. Daniele and B. Masenelli, Intense visible emission from $\mathrm{ZnO} / \mathrm{PAAX}(\mathrm{X}=\mathrm{H}$ or $\mathrm{Na})$ nanocomposite synthesized via a simple and scalable sol-gel method, Sci. Rep., 2016, 6, 23557.

65. C. Maheu, L. Cardenas, E. Puzenat, P. Afanasiev and C. Geantet, UPS and UV spectroscopies combined to position the energy levels of $\mathrm{TiO}_{2}$ anatase and rutile nanopowders, Phys. Chem. Chem. Phys., 2018, 20, 25629-25637.

66. L. Liu, W. Jiang, X. Song, Q. Duan and E. Zhu, A novel Strategy of Lock-in Effect between Conjugated Polymer and $\mathrm{TiO}_{2}$ towards Dramatic Enhancement of Photocatalytic Activity under Visible Light, Sci. Rep., 2020, 10, 6513. 